\title{
Calcium Dependence and Recovery Kinetics of Presynaptic Depression at the Climbing Fiber to Purkinje Cell Synapse
}

\author{
Jeremy S. Dittman and Wade G. Regehr \\ Department of Neurobiology, Harvard Medical School, Boston, Massachusetts 02115
}

\begin{abstract}
Short-term depression is a widespread form of use-dependent plasticity found in the peripheral and central nervous systems of invertebrates and vertebrates. The mechanism behind this transient decrease in synaptic strength is thought to be primarily the result of presynaptic "depletion" of a readily releasable neurotransmitter pool, which typically recovers with a time constant of a few seconds. We studied the mechanism and dynamics of recovery from depression at the climbing fiber to Purkinje cell synapse, where marked presynaptic depression has been described previously. Climbing fibers are well suited to studies of recovery from depression because they display little, if any, facilitation (even under conditions of low-release probability), which can obscure rapid recovery from depression for hundreds of milliseconds after release. We found that recovery from depression occurred in three kinetic phases. The fast and intermediate components could be approximated by
\end{abstract}

exponentials with time constants of $100 \mathrm{msec}$ and $3 \mathrm{sec}$ at $24^{\circ} \mathrm{C}$. A much slower recovery phase was also present, but it was only prominent during prolonged stimulus trains. The fast component was enhanced by raising extracellular calcium and was eliminated by lowering presynaptic calcium, suggesting that, on short time scales, recovery from depression is driven by residual calcium. During regular and Poisson stimulus trains, recovery from depression was dramatically accelerated by accumulation of presynaptic residual calcium, maintaining synaptic efficacy under conditions that would otherwise deplete the available transmitter pool. This represents a novel form of presynaptic plasticity in that high levels of activity modulate the rate of recovery as well as the magnitude of depression.

Key words: presynaptic depression; paired-pulse depression; Purkinje cell; climbing fiber; inferior olive neuron; Poisson stimulus
Many synapses exhibit decreased efficacy with repeated use that lasts for seconds to minutes (Del Castillo and Katz, 1954; Betz, 1970; Kusano and Landau, 1975; Thomson et al., 1993; Varela et al., 1997). Such synaptic depression was described nearly 60 years ago (Eccles et al., 1941; Feng, 1941), but the potential significance of this phenomenon is only now being appreciated. It has been suggested that synaptic depression can allow a neuron to detect synchronous rate changes in populations of synaptic inputs (Abbott et al., 1997) and can serve as a form of synaptic gain control (Markram and Tsodyks, 1996; O’Donovan and Rinzel, 1997; Varela et al., 1997). As we become aware of the potential utility of synaptic depression, there remains a need to understand the mechanisms underlying depression and how the magnitude and recovery kinetics of depression can be modulated in a usedependent manner.

One of the first and simplest presynaptic models maintains that, after exocytosis, release sites require a finite recovery time and that depression reflects an activity-dependent "depletion" of available release sites (Takeuchi, 1958; Elmqvist and Quastel, 1965; Betz, 1970). Although this model accounts for many features of depression at a variety of synapses, it greatly overestimates the amount of depression during repetitive trains. This observation gave rise to the hypothesis that recovery from depression might be more rapid during stimulus trains (Kusano and Landau, 1975; Byrne, 1982). However, the presence of prominent

\footnotetext{
Received April 17, 1998; revised May 28, 1998; accepted June 2, 1998.

This work was supported by National Institutes of Health Grant R01-NS32405-01. We thank C. Chen-Finley, A. Carter, M. Friedman, A. Kreitzer, I. Lee, B. Peters, and B. Sabatini for comments on this manuscript.

Correspondence should be addressed to Dr. Wade G. Regehr, Department of Neurobiology, Harvard Medical School, 220 Longwood Avenue, Boston MA 02115. Copyright (C) 1998 Society for Neuroscience $0270-6474 / 98 / 186147-16 \$ 05.00 / 0$
}

facilitation made it difficult to test this hypothesis, so the dynamics of synaptic depression remained poorly understood. An additional complication is that a variety of other pre- and postsynaptic factors may contribute to short-term synaptic depression, including presynaptic calcium channel inactivation (Gingrich and Byrne, 1985; Patil et al., 1998), failure of action potential initiation or conduction failure (Hatt and Smith, 1976; Smith and Hatt, 1976), negative feedback through autoinhibitory metabotropic receptors (Deisz and Prince, 1989; Davies et al., 1993; von Gersdorff et al., 1997), and receptor desensitization (Trussell and Fischbach, 1989; Trussell et al., 1993).

The synapse between inferior olivary neurons and Purkinje cells is well suited to studies of paired-pulse depression (PPD) and to clarification of the factors governing recovery from depression. Axonal terminals of inferior olivary neurons are known as climbing fibers because they appear to climb along the Purkinje cell dendrites where they form extensive synaptic contacts (Ramon y Cajal, 1911). They can be activated in an all-or-none manner triggering a series of action potentials followed by a long-lived afterhyperpolarization (Eccles et al., 1964). Elimination of active conductances reveals pronounced PPD of synaptic responses, as first described in vivo by Eccles and colleagues (Eccles et al., 1966a). More recently, this synapse has been studied in brain slices (Konnerth et al., 1990; Perkel et al., 1990; Takahashi et al., 1995; Hashimoto and Kano, 1998), where it has been shown that neither presynaptic metabotropic receptors sensitive to glutamate, GABA, or adenosine nor postsynaptic receptor desensitization contribute to PPD (Hashimoto and Kano, 1998). Moreover, manipulations that decreased the release probability also decreased PPD, indicating that for climbing fibers PPD is primarily a consequence of presynaptic mechanisms 
(Hashimoto and Kano, 1998), as seems to be the case at other synapses (Otsuka et al., 1962; Betz, 1970; von Gersdorff and Matthews, 1997; von Gersdorff et al., 1997).

Here we investigate depression at the climbing fiber to Purkinje cell synapse. The magnitude of PPD correlated with release probability, as expected from simple depletion models (Lundberg and Quilisch, 1953; Dobrunz and Stevens, 1997). In addition, recovery from depression had three distinct kinetic components, which we refer to as the fast, intermediate, and slow phases. We found that the fast and intermediate components of recovery account for the majority of depression during brief stimulus trains, whereas prolonged stimulation reveals a pronounced slow component. In this study we focus on the intermediate and fast phases, which are well approximated by exponentials with time constants of $3 \mathrm{sec}$ and $100 \mathrm{msec}$. Finally, we show that fast recovery is driven by residual calcium. This calcium-dependent recovery plays a major role in determining synaptic strength during periods of repetitive activation, when presynaptic calcium reaches high levels and greatly accelerates recovery from depression.

\section{MATERIALS AND METHODS}

Synaptic physiology. Transverse slices (300 $\mu \mathrm{m}$ thick) were cut from the cerebellar vermis of 9- to 13-d-old Sprague Dawley rats. Slices were superfused with an external solution containing (in $\mathrm{mM}$ ): $125 \mathrm{NaCl}, 2.5$ $\mathrm{KCl}, 2 \mathrm{CaCl}_{2}, 1 \mathrm{MgCl}_{2}, 26 \mathrm{NaHCO}_{3}, 1.25 \mathrm{NaH}_{2} \mathrm{PO}_{4}$, and 25 glucose, bubbled with $95 \% \mathrm{O}_{2} / 5 \% \mathrm{CO}_{2}$. Flow rates were $1-2 \mathrm{ml} / \mathrm{min}$ at $24^{\circ} \mathrm{C}$ and $5-8 \mathrm{ml} / \mathrm{min}$ at $34^{\circ} \mathrm{C}$. Bicuculline $(20 \mu \mathrm{M})$ was added to the external solution to suppress synaptic currents mediated by $\mathrm{GABA}_{\mathrm{A}}$ receptors; 4 $\mathrm{Ca}_{\mathrm{e}}$ corresponds to $4 \mathrm{~mm} \mathrm{CaCl}_{2}$ and $0 \mathrm{mM} \mathrm{MgCl}_{2}$ in the external solution, $2 \mathrm{Ca}_{\mathrm{e}}$ refers to $2 \mathrm{~mm} \mathrm{CaCl}_{2}$ and $1 \mathrm{mM} \mathrm{MgCl}_{2}$ and $1 \mathrm{Ca}_{\mathrm{e}}$ refers to $1 \mathrm{mM} \mathrm{CaCl}_{2}$ and $2 \mathrm{mM} \mathrm{MgCl}_{2}$.

Whole-cell recordings of Purkinje cells were obtained as described previously (Mintz et al., 1995) with an internal solution of (in mM): 35 $\mathrm{CsF}, 100 \mathrm{CsCl}, 10 \mathrm{EGTA}, 10 \mathrm{HEPES}$, and $0.2 \mathrm{D} 600$, adjusted to $\mathrm{pH} 7.2$ with $\mathrm{CsOH}$. Synaptic currents were monitored at a holding potential of $-40 \mathrm{mV}$ to inactivate voltage-gated $\mathrm{Na}$ channels, and D600 was included to block voltage-gated calcium channels. The access resistance and leak current $(-20$ to $-200 \mathrm{pA}$ holding at $-40 \mathrm{mV}$ ) were monitored continuously. Experiments were rejected if either access resistance or leak current increased significantly during recording.

Recording and isolation of the climbing fiber response. Two glass electrodes (tip diameter, 10-12 $\mu \mathrm{m}$ ) filled with external saline solution were placed in the granular cell layer near the Purkinje cell soma. The pipettes were connected to a stimulus current generator in a bipolar configuration. After establishing a whole-cell voltage-clamp recording from the Purkinje cell, brief pulses $(200-400 \mu \mathrm{sec})$ of current $(1-10 \mu \mathrm{A})$ were passed between the electrodes. They were repositioned until a climbing fiber EPSC (CF-EPSC) was activated. A typical CF-EPSC recorded at a holding potential of $-40 \mathrm{mV}$ is shown in Figure 1 Peak CF-EPSC magnitudes typically ranged from 6 to $12 \mathrm{nA}$. Because of the large size and rapid time course of the CF-EPSC, we used low-resistance recording electrodes (resistance was $0.8-1.2 \mathrm{M} \Omega$ with a tip diameter $>3 \mu \mathrm{m}$ ) and maximal series resistance compensation to minimize voltage-clamp errors. In addition, a small amount $(0.5-2 \mu \mathrm{M})$ of the competitive AMPA/ kainate receptor antagonist CNQX was added to the superfusate to reduce the magnitude of the CF-EPSC. Figure $1 A$ demonstrates that an eightfold reduction in CF-EPSC size after addition of $3 \mu \mathrm{M} \mathrm{CNQX}$ had only minor effects on the time course of the CF-EPSC. At $24^{\circ} \mathrm{C}$, there was variability in the time course of the EPSCs in well-clamped cells, with decay time constants of the EPSCs ranging from 4 to 8 msec.

In addition to activating CF-EPSC, stimulation within the granule cell layer can activate glutamatergic parallel fiber EPSCs (PF-EPSC). Contamination with PF-EPSCs, which exhibit a large paired-pulse facilitation (PPF), can result in an underestimate of the true climbing fiber PPD. This problem is accentuated in conditions of low external calcium, in which climbing fiber PPD is small, but parallel fiber PPF is pronounced (Atluri and Regehr, 1996); even a small parallel fiber contamination can make a CF-EPSC appear facilitated in low external calcium. With this potential complication in mind, we minimized parallel fiber contamina-
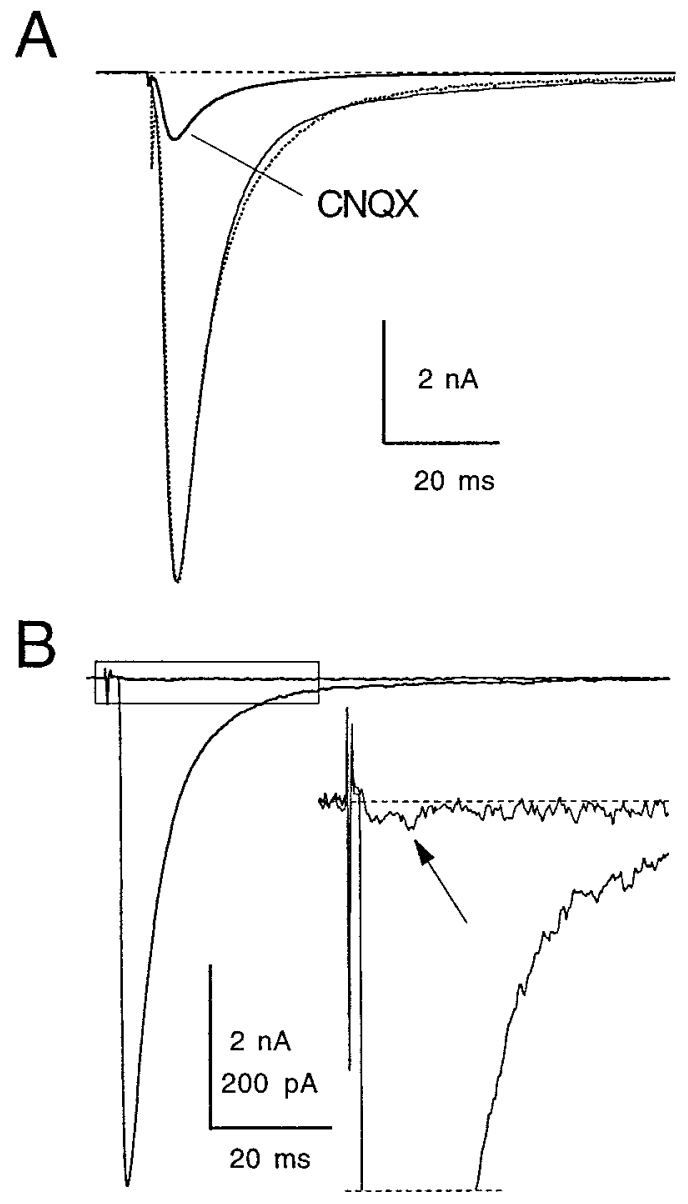

Figure 1. Stimulation of climbing fiber synaptic currents. $A$, Evoked climbing fiber EPSC before (thin line) and during (thick line) bath application of $3 \mu \mathrm{M}$ CNQX. The synaptic response in CNQX was scaled to the control response (dotted line) for comparison of the EPSC waveform. Traces are averages of 10 trials each. $B$, Consecutive traces taken during perithreshold stimulation of a climbing fiber demonstrating the all-ornone behavior of CF-EPSCs. The inset is taken from the boxed region indicated. The arrow indicates the climbing fiber failure.

tion by adjusting stimulus strength to threshold and analyzing failures by the presence of PF-EPSCs. Figure $1 B$ shows two consecutive stimuli. The first elicited a CF-EPSC; the second failed to drive the CF, and no underlying PF-EPSC was apparent. In all experiments, PF-EPSCs were $<0.5 \%$ of the CF-EPSC. In addition, cells with more than one CF were rejected.

Cyclothiazide experiments. Cyclothiazide (CTZ) was used in some experiments to explore the contributions of postsynaptic receptor desensitization to PPD. In the presence of 20-60 $\mu \mathrm{M}$ CTZ, CF-EPSC decay times were significantly prolonged, and peak synaptic currents were somewhat reduced (see Fig. $5 A$, left). In contrast, when CNQX was included in the superfusate to reduce CF-EPSC amplitude, application of CTZ consistently increased the peak synaptic currents as well as the time constant of decay (see Fig. 5A, right). A possible explanation for this increase is that CTZ either competes with CNQX for a binding site on the AMPA receptor or allosterically decreases the affinity of CNQX, thereby reducing steady-state blockade (Yamada and Rothman, 1992; Yamada and Turetsky, 1996).

Data acquisition and analysis. Outputs of the Axopatch 200A were filtered at $1 \mathrm{kHz}$ and digitized at $5 \mathrm{kHz}$ with a 16-bit digital-to-analog converter (Instrutech, Great Neck, NY) using Pulse Control software (Herrington and Bookman, 1995). Random train stimuli were generated off-line and sent through the DAC to the stimulus isolation unit in $10 \mathrm{sec}$ epochs, whereas the holding potential was maintained at $-40 \mathrm{mV}$. Both 
on- and off-line analysis as well as computer simulations were done using Igor Pro software (Wavemetrics, Lake Oswego, OR).

Calcium-dependent model of presynaptic depression. According to Scheme II (see Results) and assuming that this scheme accounts for all possible states of the release apparatus, $R+T+N=N_{o}$, where $R$ sites are in a refractory state, $T$ sites are in a transitional state, $N$ sites are release ready, and there are a total of $N_{o}$ release sites. Calcium dynamics must also be considered to account for recovery from depression according to Scheme II. After a presynaptic action potential arrives, free calcium rapidly jumps from its resting value $\left.\left(\mathrm{Ca}_{\text {rest }}\right)\right)$ to an initial concentration $\left(\mathrm{Ca}_{o}+\mathrm{Ca}_{\text {rest }}\right)$ and decays exponentially with time constant $\tau_{c}$ back to $\mathrm{Ca}_{\text {rest }}$ (Neher and Augustine, 1992; Tank et al., 1995). The assumption of a single exponential decay was made for simplicity, but at some presynaptic terminals, calcium transients are better approximated by a double exponential decay (Atluri and Regehr, 1996). The postulates about the recovery dynamics of the climbing fiber presynaptic terminal can be expressed quantitatively in the following manner:

$$
\begin{gathered}
\tau_{c} \frac{\mathrm{dCa}}{\mathrm{d} t}=\mathrm{Ca}_{\text {rest }}-\mathrm{Ca}(t)+\mathrm{Ca}_{o} \delta\left(t-t_{o}\right), \\
\frac{\mathrm{d} N}{\mathrm{~d} t}=\left(N_{o}-N(t)-N(t) p_{o} \delta\left(t-t_{o}\right)\right) \cdot k_{\text {recov }}(\mathrm{Ca}), \\
k_{\text {recov }}(\mathrm{Ca})=\frac{k_{\max }}{1+K_{N} / \mathrm{Ca}(t)},
\end{gathered}
$$

where an action potential arrives at the presynaptic terminal at time $t_{o}$. Rapid equilibration with calcium is assumed, and in analogy with the Michaelis-Menten reaction scheme, $T$ is assumed to be in steady state, with $\mathrm{d} T / \mathrm{d} t=0$ (Schulz, 1994). Here, the kinetic constant $K_{N}=\left(k^{-}+\right.$ $\left.k_{\max }\right) / k^{+}$.

Equations 1 and 2 can be solved analytically for the response to a single action potential, but the solution can be simplified enormously with one further approximation. If resting calcium is very low relative to the total calcium influx after an action potential $\left(\mathrm{Ca}_{\text {rest }} \ll \mathrm{Ca}_{o}\right)$, then recovery can be divided into two separate phases: a rapid recovery occurring when $\mathrm{Ca}$ is near $\mathrm{Ca}_{o}$, and a slower phase occurring when $\mathrm{Ca}$ has decayed to low levels that we call the intermediate recovery phase. Under this assumption, Equations 1 and 3 can be approximated by:

$$
\begin{gathered}
\tau_{c} \frac{\mathrm{dCa}}{\mathrm{d} t}=-\mathrm{Ca}(t)+\mathrm{Ca}_{o} \delta\left(t-t_{o}\right), \\
k_{\mathrm{recov}}(\mathrm{Ca})=\frac{k_{\max }-k_{o}}{1+K_{N} / \mathrm{Ca}(t)}+k_{o},
\end{gathered}
$$

where calcium jumps from 0 to $\mathrm{Ca}_{o}$ and decays back to 0 , whereas $k_{\text {recov }}$ can range between a minimal rate $k_{o}$ and the same maximal rate $k_{\max }$ as in Equation 3. This simplification can be interpreted in two ways. First, resting calcium may not contribute to the intermediate recovery kinetics observed at this synapse, so $k_{o}$ would represent the recovery rate of a separate, calcium-independent pathway used when residual calcium falls to a low concentration. Alternatively, both the fast and intermediate phases of recovery may depend on calcium, as indicated in Scheme II, and $k_{o}$ would correspond to the recovery rate when $\mathrm{Ca}=\mathrm{Ca}_{\text {rest }}$ [from Equation $\left.3, k_{o}=k_{\max }\left(1+K_{N} / \mathrm{Ca}_{\text {rest }}\right)^{-1}\right]$. Our data did not distinguish between these two interpretations because we had no means of altering or eliminating resting calcium. After this simplification, equations 2, 4, and 5 can be solved for the response to a single action potential, yielding:

$$
\frac{N(t)}{N_{o}}=1-p_{o} \exp \left(-k_{o} t\right) \cdot\left(\frac{K_{N} / \mathrm{Ca}_{o}+1}{K_{N} / \mathrm{Ca}_{o}+\exp \left(-t / \tau_{c}\right)}\right)^{-\left(k_{\max }-k_{o}\right) \tau_{c}}
$$

The paired-pulse depression recovery curves (see Fig. 9) were fit to Equation 6 with three free parameters: $K_{N} / \mathrm{Ca}_{o}, k_{\max }$, and $\tau_{c}$. Note that $k_{o}$ and $p_{o}$ were constrained by the data because PPD at early times gives a rough estimate of $p_{o}$ and residual calcium has decayed to baseline levels within the first few seconds so the recovery rate is essentially $k_{o}$. When external calcium was altered, $p_{o}$ and $\mathrm{Ca}_{o}$ were changed accordingly, while $K_{N}, k_{\max }$, and $\tau_{c}$ were fixed. When EGTA-AM was added, $\tau_{c}$ was decreased by a factor comparable with that seen in parallel fibers (Atluri and Regehr, 1996), and $p_{o}$ was decreased slightly, consistent with the observed effect of EGTA-AM on the evoked EPSC (see Results).
For trains of stimuli, Equation 4 can be solved explicitly for the value of residual calcium immediately after the $i$ th pulse (Regehr et al., 1994):

$$
\mathrm{Ca}_{i}=\mathrm{Ca}_{i-1} \cdot \exp \left[-\left(t_{i}-t_{i-1}\right) / \tau_{c}\right],
$$

where $t_{i-1}$ and $t_{i}$ are the $(i-1)$ th and $i$ th stimulus times, respectively. In the special case of evenly spaced stimuli given at rate $r$, calcium just after the $i$ th pulse is given by:

$$
\mathrm{Ca}_{i}=\mathrm{Ca}_{\infty}\left[1-\exp \left(-i / r \tau_{c}\right)\right]
$$

where $\infty$ is the steady-state value of calcium reached after a large number of stimuli:

$$
\mathrm{Ca}_{\infty}=\mathrm{Ca}_{o}\left[1-\exp \left(-1 / r \tau_{c}\right)\right]^{-1} .
$$

After each stimulus, the number of available release sites decreases by a fraction proportional to the release probability (i.e., $\Delta N_{i}=-N_{i} p_{o}$ ), and each release site recovers with a rate that depends on the value of residual calcium. Using Equations 2 and 5:

$$
\frac{N_{i}}{N_{o}}=1-\left(1-\left(1-p_{o}\right) \cdot N_{i-1}\right) \cdot \exp \left(-k_{o} / r\right) \cdot \xi_{i}(r),
$$

where:

$$
\xi_{i}(r)=\left(\frac{K_{N} / \mathrm{Ca}_{i-1}+1}{K_{N} / \mathrm{Ca}_{i-1}+\exp \left(-1 / r \tau_{c}\right)}\right)^{-\left(k_{\max }-k_{o}\right) \tau_{\mathrm{c}}}
$$

and $N_{i}$ is the number of available sites immediately before the $i$ th stimulus. Equation 10 was used to calculate depression during trains (see Figs. 7, 8, 10-12 with the parameters given in Fig. 9). After a sufficient number of stimuli, the number of available sites reaches a steady-state value given by:

$$
\frac{N_{\infty}}{N_{o}}=\frac{1-\exp \left(-k_{o} / r\right) \cdot \xi_{\infty}(r)}{1-\left(1-p_{o}\right) \exp \left(-k_{o} / r\right) \cdot \xi_{\infty}(r)} .
$$

In the case of calcium-independent recovery (or in the limit $K_{N} \rightarrow \infty$ so $\xi_{\infty} \rightarrow 1$ ), equation (11) reduces to:

$$
\frac{N_{\infty}}{N_{o}}=\frac{1-\exp \left(-k_{o} / r\right)}{1-\left(1-p_{o}\right) \cdot \exp \left(-k_{o} / r\right)} .
$$

Equations (11) and (12) were used to calculate steady-state attenuation as a function of frequency for the calcium-dependent (Scheme II) and calcium-independent recovery models (Scheme I), respectively (see Fig. 12B).

\section{RESULTS}

\section{Paired-pulse depression and release probability}

Experiments were performed to determine the dependence of $\mathrm{PPD}$, defined as $\left(\mathrm{EPSC}_{1}-\mathrm{EPSC}_{2}\right) / \mathrm{EPSC}_{1}$, on presynaptic calcium influx and release probability (Fig. 2). Under control conditions, with $2 \mathrm{~mm}$ external calcium $\left(\mathrm{Ca}_{\mathrm{e}}\right)$ and $1 \mathrm{~mm}$ external magnesium $\left(\mathrm{Mg}_{\mathrm{e}}\right)$, there is $\sim 50 \%$ depression for pulses separated by $30 \mathrm{msec}$. When $\mathrm{Ca}_{\mathrm{e}}$ was lowered to $0.5 \mathrm{~mm}$ and $\mathrm{Mg}_{\mathrm{e}}$ raised to $2.5 \mathrm{~mm}$, both the peak EPSC and PPD decreased significantly (Fig. $2 A$ ). Although the EPSC was reduced by approximately a factor of three, no underlying facilitation was revealed (see Materials and Methods). At intermediate $\mathrm{Ca}_{\mathrm{e}}\left(1 \mathrm{~mm} \mathrm{Ca}_{\mathrm{e}}\right.$ and $2 \mathrm{~mm}$ $\mathrm{Mg}_{\mathrm{e}}$ ), peak EPSCs and PPD decreased moderately (Fig. $2 B$ ), whereas high $\mathrm{Ca}_{\mathrm{e}}\left(4 \mathrm{~mm} \mathrm{Ca}_{\mathrm{e}}\right.$ and $0 \mathrm{~mm} \mathrm{Mg}$ ) slightly raised the magnitude of PPD and had little effect on peak EPSCs (Fig. 2C).

The relationship between $\mathrm{Ca}_{\mathrm{e}}$ and peak EPSC suggests that the climbing fiber to Purkinje cell synapse operates at a high baseline release probability. Although raising $\mathrm{Ca}_{\mathrm{e}}$ from 0.5 to $1 \mathrm{~mm}$ greatly enhanced synaptic strength, further increases in $\mathrm{Ca}_{\mathrm{e}}$ had little effect on synaptic strength. This behavior is a hallmark of a synapse that operates near saturation and is in sharp contrast to 
A
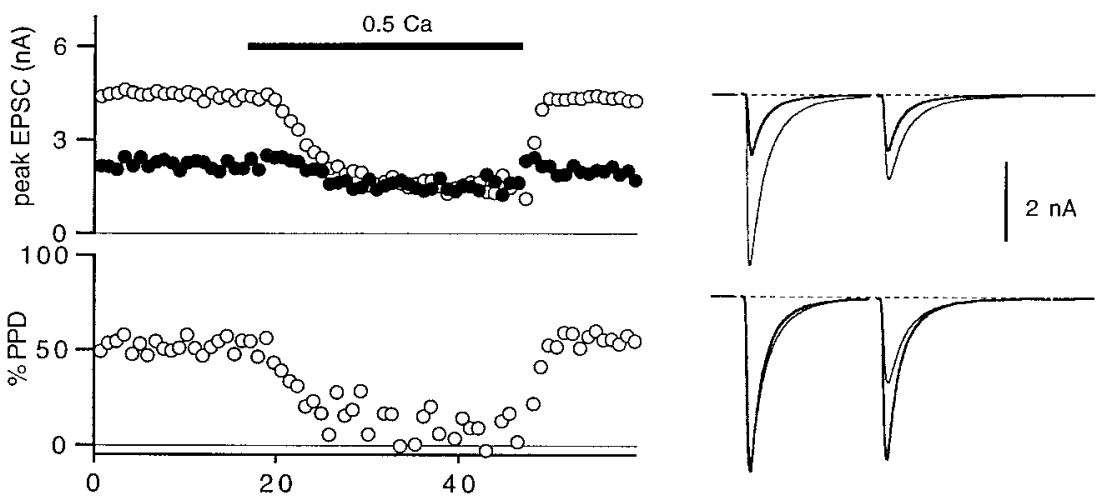

Figure 2. Dependence of release probability and PPD on external Ca. A, Top left, Peak EPSC time course for a pair of EPSCs recorded with a $30 \mathrm{msec}$ interstimulus interval in $2 \mathrm{Ca}_{\mathrm{e}}$. EPSC $\mathrm{C}_{1}$ is indicated by open circles, and $\mathrm{EPSC}_{2}$ is indicated by filled circles. Low Ca external solution $(0.5 \mathrm{~mm} \mathrm{Ca} ; 2.5 \mathrm{~mm} \mathrm{Mg})$ was applied during the time indicated by the thick horizontal line. Bottom left, Paired-pulse depression plotted for each data point. Top right, Average of 10 traces taken before (thin lines) and during (thick lines) exposure to low $\mathrm{Ca}_{\mathrm{e}}$. Bottom right, Traces replotted normalized to the peak of the first EPSC. B, Application of 1 $\mathrm{Ca}_{\mathrm{e}}$. $C$, Application of $4 \mathrm{Ca}_{\mathrm{e}}$.
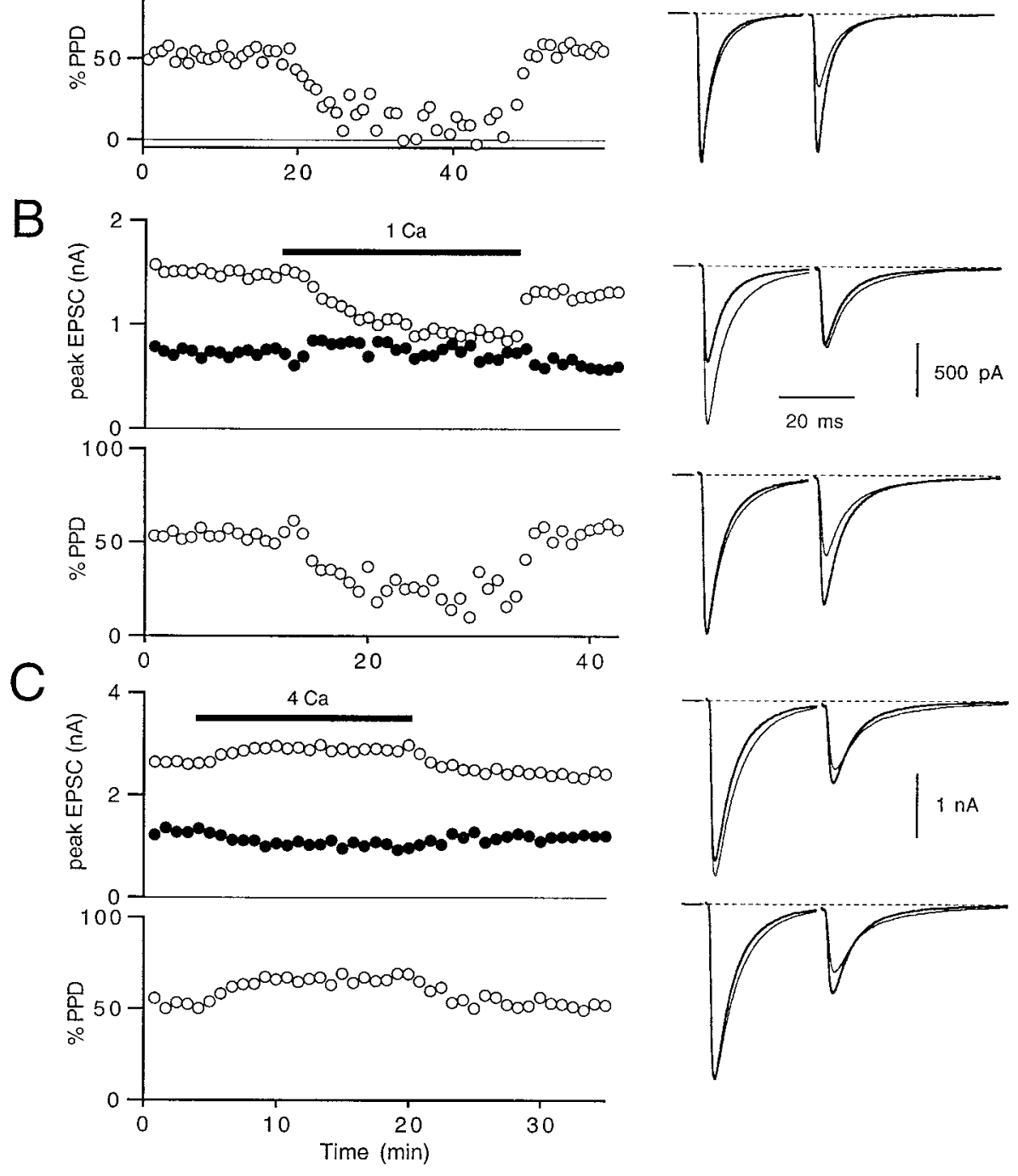

nonsaturated synapses, where doubling $\mathrm{Ca}_{\mathrm{e}}$ can enhance synaptic strength 10-fold (Zucker, 1989).

It is interesting to consider these findings in terms of the depletion model, for which the magnitude of PPD at very brief interpulse intervals approximates the probability of release (see Materials and Methods). With our definition of PPD, if the second stimulus occurs when there has not been sufficient time for recovery, then $\mathrm{PPD} \approx p_{o}$, where $p_{o}$ is defined as the probability that a site releases its transmitter given that it is release ready (see Discussion and subsequent sections of Results for a more detailed discussion). Based on the depletion model and with the assumption that very little recovery has occurred at $30 \mathrm{msec}$, the probabilities of release are estimated to be $0.04,0.3,0.5$, and 0.7 in 0.5 , 1,2 , and $4 \mathrm{~mm} \mathrm{Ca}_{\mathrm{e}}$, respectively. Thus, the data in Figure 2 are qualitatively consistent with this model to the extent that there is less PPD when $p_{o}$ is reduced in low $\mathrm{Ca}_{\mathrm{e}}$ (Lundberg and Quilisch, 1953; Thies, 1965).

\section{Kinetics of recovery from paired-pulse depression}

In addition to the degree of depression, another important factor is the time course of PPD. Our estimates of $p_{o}$ may underestimate the true release probability if some recovery has occurred within $30 \mathrm{msec}$. To examine recovery from depression, we calculated the time course of PPD for a variety of different interpulse intervals in the presence of different concentrations of $\mathrm{Ca}_{\mathrm{e}}$ (Fig. 3). Under all conditions tested, recovery from depression had a phase that persisted for many seconds (termed intermediate recovery phase). An additional fast recovery phase was apparent in $2 \mathrm{~mm}$ $\mathrm{Ca}_{\mathrm{e}}$ (Fig. $3 B$ ) and was more pronounced in $4 \mathrm{~mm} \mathrm{Ca}_{\mathrm{e}}$ (Fig. $3 C$ ). Averages of multiple experiments of this type revealed similar 

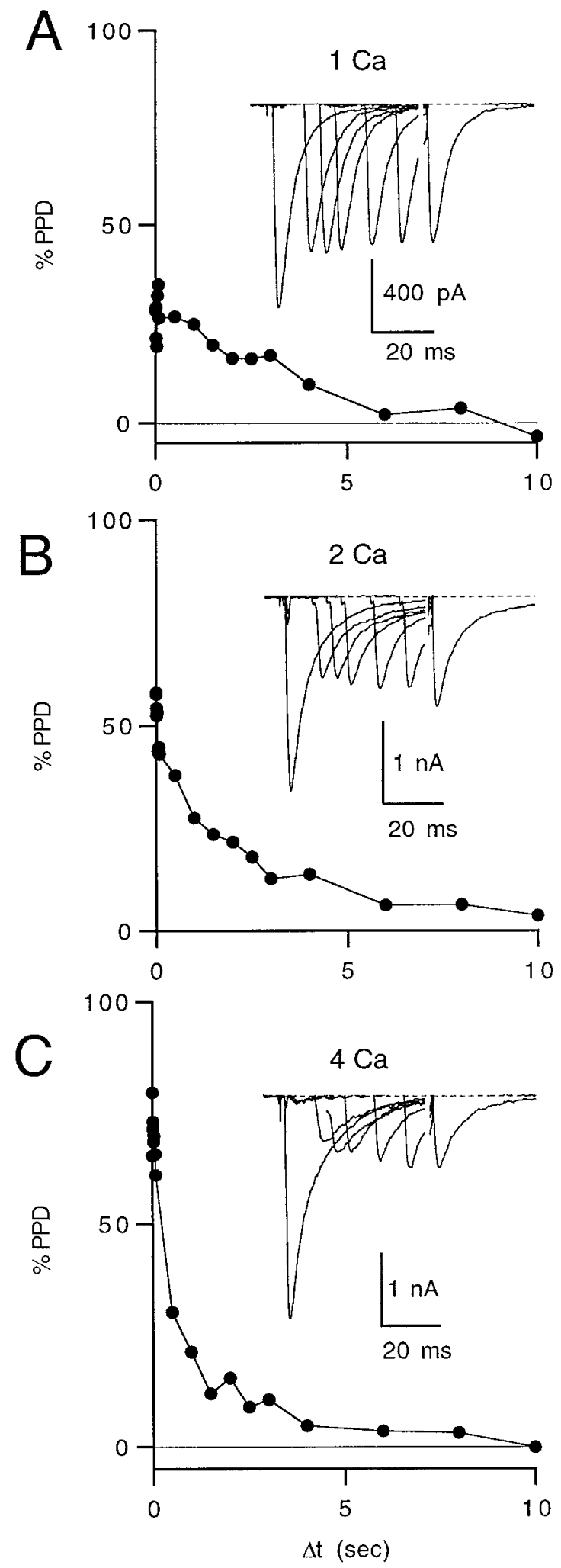

Figure 3. Kinetics of recovery from paired-pulse depression. Representative experiments showing recovery from depression in $1 \mathrm{Ca}_{\mathrm{e}}(A), 2 \mathrm{Ca}_{\mathrm{e}}$ $(B)$, and $4 \mathrm{Ca}_{\mathrm{e}}(C)$. Insets are single traces for paired-pulse intervals of 10 , $15,20,30,40$, and $50 \mathrm{msec}$ after control stimulation. \%PPD $=100\left(\mathrm{EPSC}_{1}\right.$ $\left.-\mathrm{EPSC}_{2}\right) / \mathrm{EPSC}_{1}$, where $\mathrm{EPSC}_{1}$ and $\mathrm{EPSC}_{2}$ are, respectively, the amplitudes of the control and depressed EPSCs. trends in recovery kinetics. Under conditions of low-release probability and small presynaptic calcium influx $\left(1 \mathrm{mM} \mathrm{Ca}_{\mathrm{e}}\right)$, PPD is well approximated by a single exponential with a time constant $\tau$ $=3.6 \mathrm{sec}$ and amplitude $\mathrm{A}=36 \%$ (Fig. $4 A$, top). In $2 \mathrm{mM} \mathrm{Ca}_{\mathrm{e}}$, recovery from depression is approximated by a double exponential: a fast component with $A_{\text {fast }}=21 \%$ and $\tau_{\text {fast }}=100 \mathrm{msec}$ and an intermediate component with amplitude $A_{\text {inter }}=40 \%$ and $\tau_{\text {inter }}=3.2 \mathrm{sec}$ (Fig. $4 A$, middle). In $4 \mathrm{~mm} \mathrm{Ca}_{\mathrm{e}}$, PPD decay is also described by a sum of two exponentials, with $A_{\text {fast }}=44 \%, \tau_{\text {fast }}=$ $87 \mathrm{msec}, A_{\text {inter }}=38 \%$, and $\tau_{\text {inter }}=2.5 \mathrm{sec}$ (Fig. $4 A$, bottom). Superposition of all three PPD curves illustrates the similarity of the intermediate recovery phase (Fig. $4 B$ ) and the systematic increase in amplitude of the fast recovery phase (Fig. 4B, inset). Depression at interpulse intervals of $<10 \mathrm{msec}$ was not explored because climbing fiber activation was unreliable, and we had no independent means of confirming that an action potential successfully reached the presynaptic terminals after the second stimulus. Under all conditions, a small degree of depression $(<5 \%)$ was still present after $10 \mathrm{sec}$. This residual depression may have reflected a slow recovery phase that became prominent during long stimulus trains.

The major features of depression found at $24^{\circ} \mathrm{C}$ were also present at $34^{\circ} \mathrm{C}$, although recovery was accelerated significantly. At $34^{\circ} \mathrm{C}$ in $2 \mathrm{Ca}_{\mathrm{e}}, A_{\text {fast }}=15 \%$ and $\tau_{\text {fast }}=44 \mathrm{msec}$, and an intermediate component exists with amplitude $A_{\text {inter }}=36 \%$ and $\tau_{\text {inter }}=1.2 \mathrm{sec}(n=5$; data not shown). Similarly, in vivo measurements of PPD at this synapse in adult cats showed two components of recovery from depression with $A_{\text {fast }}$ of $\sim 20 \%$ and $\tau_{\text {fast }}$ of $\sim 20 \mathrm{msec}$ and with $A_{\text {inter }}$ of $\sim 30 \%$ and $\tau_{\text {inter }}$ of $\sim 0.5 \mathrm{sec}$ (Eccles et al., 1966a,b).

\section{Postsynaptic contributions to the rapid recovery phase}

One possible explanation for the rapid recovery phase of PPD is that it reflects recovery from postsynaptic receptor desensitization. Consistent with this hypothesis is the observation that it takes tens of milliseconds for AMPA receptors to recover from desensitization, and desensitization can be more pronounced under conditions of enhanced neurotransmitter release (Trussell et al., 1993). To test the contribution of desensitization to PPD at the climbing fiber to Purkinje cell synapse, we determined the effect of the benzodiathiazide diuretic CTZ on PPD. CTZ slows the rate of desensitization for AMPA receptors (Yamada and Rothman, 1992) and has a number of additional effects (Diamond and Jahr, 1995). If the rapidly recovering component of PPD is attributable to recovery from desensitization, then it should be greatly reduced or eliminated by CTZ, and the magnitude of PPD should be reduced for short interpulse intervals.

CTZ (20-60 $\mu \mathrm{M})$ consistently prolonged EPSC decay times with or without CNQX (Fig. $5 A$ ). However, CTZ had little effect on the magnitude of PPD present for brief interpulse intervals (Fig. $5 B$ ). Figure 5, $C$ and $D$, shows averages of multiple PPD time-course experiments performed with $40 \mu \mathrm{M} \mathrm{CTZ} \mathrm{under} \mathrm{con-}$ trol conditions $\left(2 \mathrm{~mm} \mathrm{Ca}_{\mathrm{e}}\right)$ and in high $\mathrm{Ca}_{\mathrm{e}}(4 \mathrm{~mm})$. In all experiments $(n=7)$, CTZ did not attenuate the fast recovery component relative to that in control conditions (39\% fast component in $2 \mathrm{Ca}_{\mathrm{e}} ; 50 \%$ fast component in $4 \mathrm{Ca}_{\mathrm{e}}$ ); in fact, the fast component was more pronounced after treatment with $\mathrm{CTZ}$ in both 2 and $4 \mathrm{Ca}_{\mathrm{e}}$. These results suggest that postsynaptic receptor desensitization does not contribute significantly to the rapid recovery phase of paired-pulse depression for intervals $>10 \mathrm{msec}$. Furthermore, the change in PPD suggests that CTZ acts pre- 

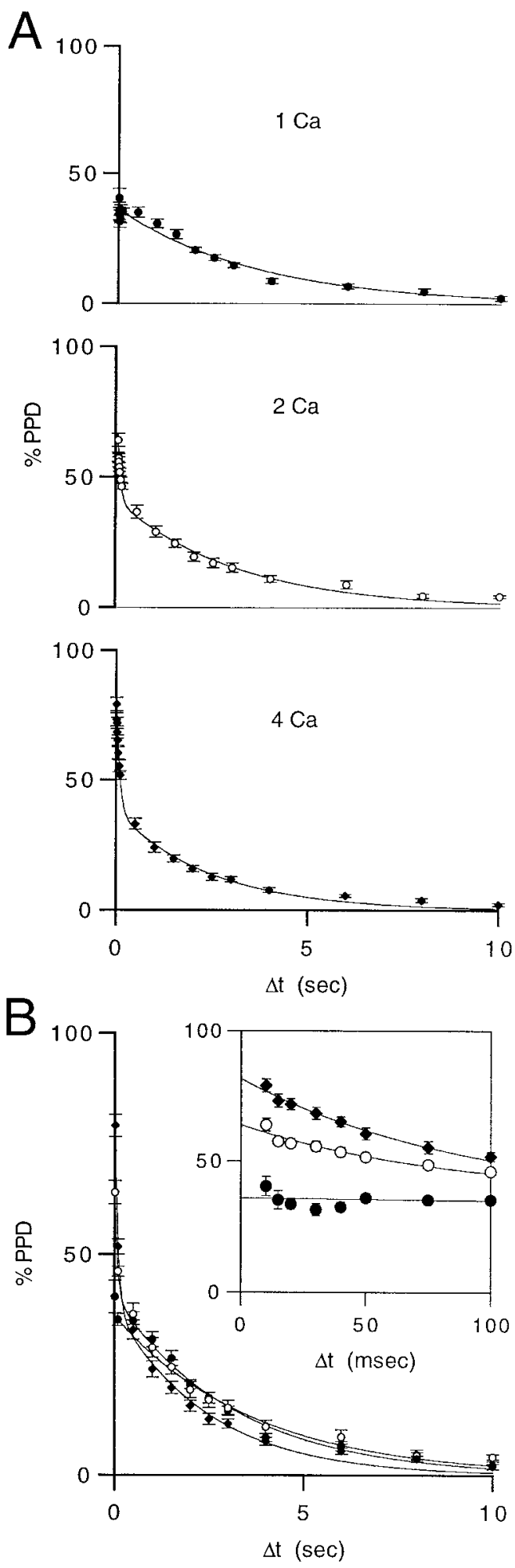

Figure 4. Dependence of recovery kinetics on external calcium. A, Average recovery of depression in $1 \mathrm{Ca}_{\mathrm{e}}($ top $; n=9), 2 \mathrm{Ca}_{\mathrm{e}}$ (middle; $\left.n=11\right)$, and $4 \mathrm{Ca}_{\mathrm{e}}$ (bottom; $n=12$ ). Error bars indicate SEM. In $1 \mathrm{Ca}_{\mathrm{e}}$, data were fit to $\% \mathrm{PPD}=A \mathrm{e}^{-\mathrm{t} / \tau}$, with $A=36 \%$, and $\tau=3.6 \mathrm{sec}$. In 2 and $4 \mathrm{Ca}_{\mathrm{e}}$, data were fit to $\% \mathrm{PPD}=A_{\text {fast }} \mathrm{e}^{-\mathrm{t} / \tau_{\text {fast }}}+A_{\text {inter }} \mathrm{e}^{-\mathrm{t} / \tau_{\text {inter }}}$. In $2 \mathrm{Ca}_{\mathrm{e}}, A_{\text {fast }}=21 \%$, $A_{\text {inter }}=40 \%, \tau_{\text {fast }}=99 \mathrm{msec}$, and $\tau_{\text {inter }}=3.2 \mathrm{sec}$. In $4 \mathrm{Ca}_{\mathrm{e}}, A_{\text {fast }}=44 \%$, $A_{\text {inter }}=38 \%, \tau_{\text {fast }}=87 \mathrm{msec}$, and $\tau_{\text {inter }}=2.5 \mathrm{sec} . B$, Superimposed PPD curves for the three external calcium conditions. Inset, Early time points for the rapid phase of recovery from depression in $1 \mathrm{Ca}_{\mathrm{e}}$ (filled circles), 2 $\mathrm{Ca}_{\mathrm{e}}$ (open circles), and $4 \mathrm{Ca}_{\mathrm{e}}$ (filled diamonds). synaptically to enhance transmitter release. Similar presynaptic effects have been reported at other synapses (Diamond and Jahr, 1995).

\section{Dependence of rapid recovery on presynaptic calcium dynamics}

The enhancement of the rapid recovery phase with increased $\mathrm{Ca}_{\mathrm{e}}$ suggests two main possibilities for its underlying mechanism. (1) Recovery from depression is dependent on intracellular calcium levels, and increased $\mathrm{Ca}_{\mathrm{e}}$ leads to larger stimulus-evoked calcium transients that accelerate recovery, and (2) recovery from depression is somehow coupled to the probability of release (a higher $p_{o}$ leads to a more pronounced rapid component of recovery). We distinguished between these possibilities by introducing EGTA into presynaptic terminals using EGTA-AM. Because EGTA binds calcium with slow kinetics, moderate concentrations of the chelator can be introduced into the presynaptic terminal without significantly affecting the large, brief, and localized calcium transients that dictate release probability (Adler et al., 1991). As we have shown previously, calcium levels in the tens to hundreds of milliseconds after stimulation (residual calcium) are much more effectively reduced by EGTA, and the slow calcium-binding kinetics of EGTA allow it to speed the decay of calcium (Atluri and Regehr, 1996). For example, exposure to $100 \mu \mathrm{M}$ EGTA-AM for 10 min shortens the half-decay time of presynaptic calcium transients in parallel fibers evoked by a single stimulus from 40 to 2 msec.

Figure $6 A$ shows an example of a PPD time course determined before and after bath application of $100 \mu \mathrm{M}$ EGTA-AM in the presence of $4 \mathrm{~mm} \mathrm{Ca}_{\mathrm{e}}$. The magnitude of depression at $10 \mathrm{msec}$ was unaltered, but recovery from depression was slowed. The lack of an EGTA effect during the first few paired-pulse stimuli is consistent with its slow on-rate, which prevents EGTA from affecting the early phase of residual calcium decay. By monitoring PPD at an interpulse interval of $500 \mathrm{msec}$ during a bath application of EGTA-AM, we observed a nearly two-fold increase in the magnitude of depression accompanied by a slight decrease in the EPSC amplitude (Fig. 6B). PPD at $500 \mathrm{msec}$ increased by a factor of $1.9 \pm 0.2($ mean $\pm \mathrm{SEM} ; n=7)$. The PPD curves measured in $4 \mathrm{Ca}_{\mathrm{e}}$ with and without loading with EGTA-AM are compared in Figure $6 C$. The EGTA PPD curve was fit to a sum of two exponentials with $A_{\text {fast }}=17 \%, \tau_{\text {fast }}=17 \mathrm{msec}, A_{\text {inter }}=65 \%$, and $\tau_{\text {inter }}=2.9 \mathrm{sec}$. In comparison with the $4 \mathrm{Ca}_{\mathrm{e}}$ PPD curve $\left(A_{\text {fast }}=\right.$ $44 \%, \tau_{\text {fast }}=87 \mathrm{msec}, A_{\text {inter }}=38 \%$, and $\left.\tau_{\text {inter }}=2.5 \mathrm{sec}\right)$, the rapid recovery phase has been greatly reduced in amplitude and accelerated. Figure $6 D$ shows the same curves on a semilog plot to emphasize the similar time courses of the intermediate recovery phase. We conclude that this effect of EGTA on PPD was presynaptic in origin because EGTA-AM would not alter EGTA levels in the postsynaptic cell, which are set by the contents of the recording pipette. Furthermore, it is highly unlikely that the minor reduction in the probability of release by EGTA-AM could account for the changes in PPD time course; EGTA-AM reduced the EPSC amplitude by just $11 \%(n=5)$ and reduced the magnitude of PPD at short interpulse intervals from 81 to $78 \%$ in $4 \mathrm{Ca}_{\mathrm{e}}$. Hence, these experiments establish that rapid recovery from depression depends on presynaptic residual calcium, independent of the initial release probability.

\section{Dynamics of use-dependent recovery during trains}

The dynamics of recovery from depression and the predictions of the calcium-dependent model were further explored using brief 
A
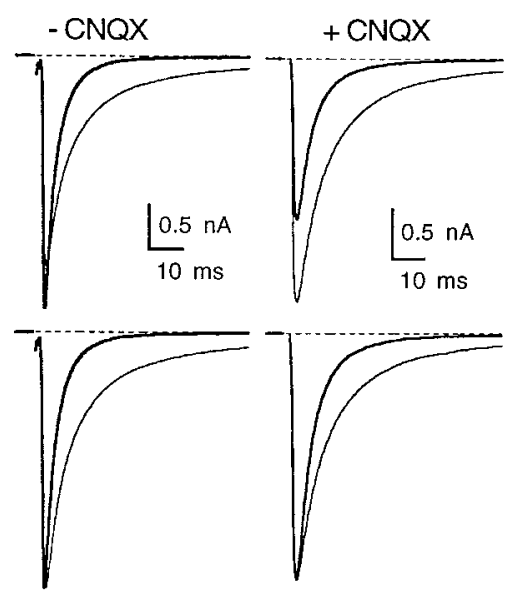

C

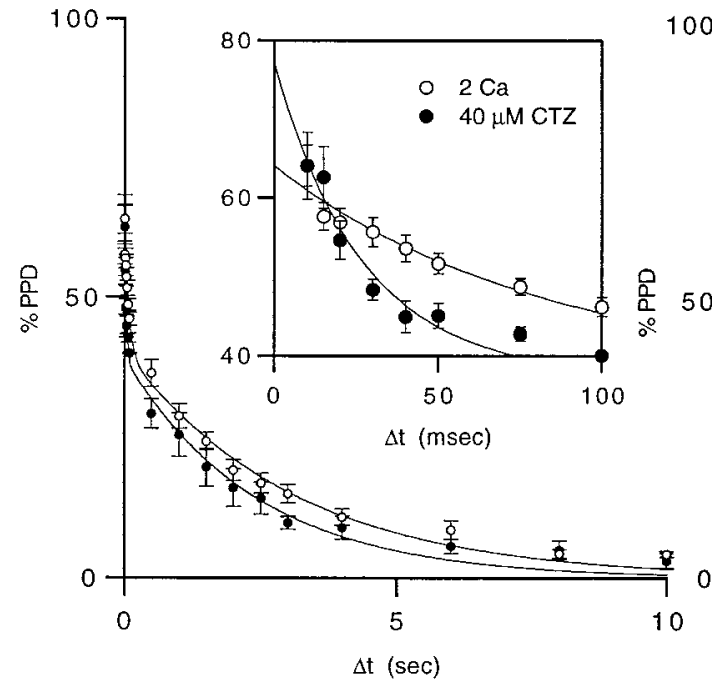

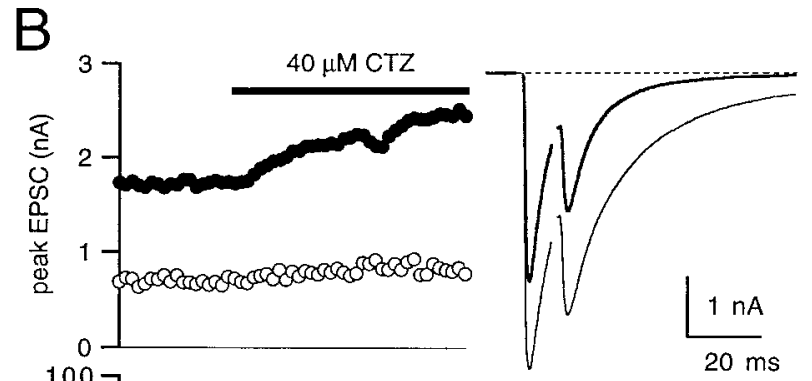
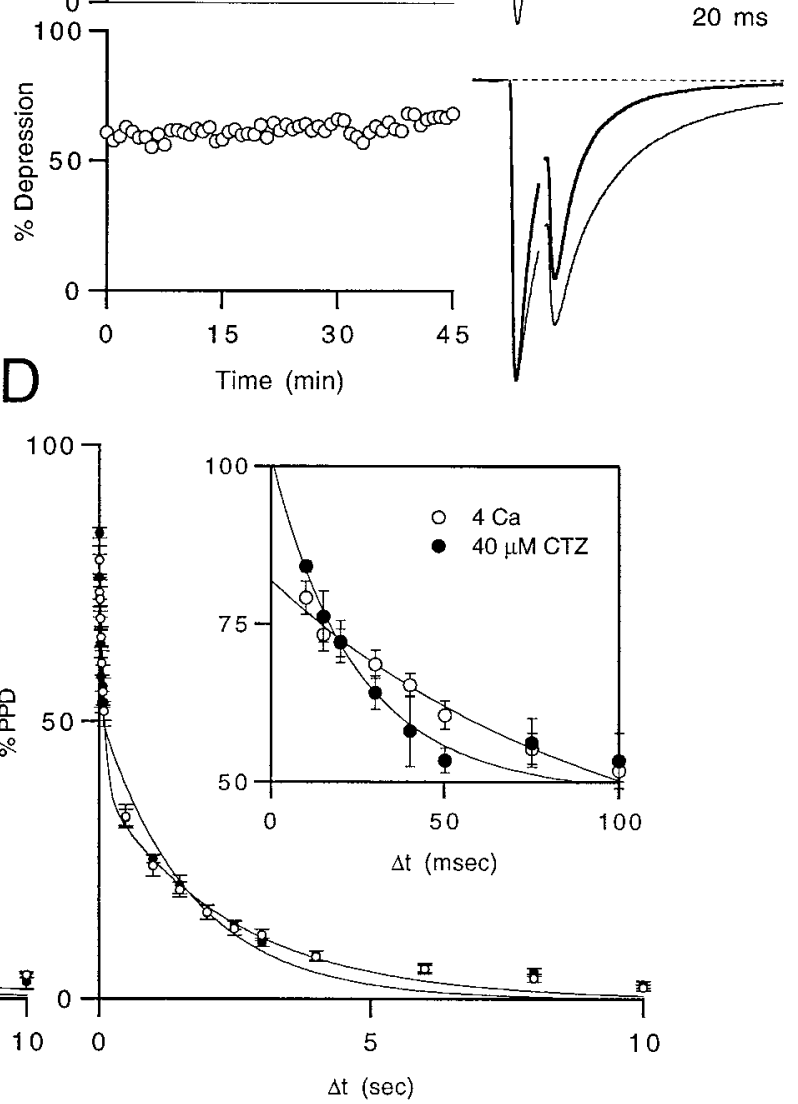

Figure 5. Effects of cyclothiazide on the rapid phase of recovery from depression. A, Top, Synaptic currents recorded in the absence (left) and presence (right) of $1 \mu \mathrm{M} \mathrm{CNQX}$ before (thick line) and during (thin line) exposure to $40 \mu \mathrm{M} \mathrm{CTZ.} \mathrm{CTZ} \mathrm{slowed} \mathrm{the} \mathrm{decay} \mathrm{times} \mathrm{from} 4$ to 9 msec (left) and from 6 to $11 \mathrm{msec}($ right). Bottom, Traces normalized for comparison. The effect of CTZ on the amplitude of the EPSC is discussed in Materials and Methods.

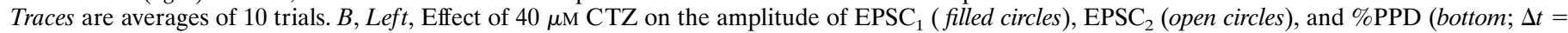
$15 \mathrm{msec}$ ). Right, Averages of 10 traces in control (thin lines) and $40 \mu \mathrm{M} \mathrm{CTZ} \mathrm{(thick} \mathrm{lines).} \mathrm{Lower} \mathrm{trace,} \mathrm{Same} \mathrm{traces} \mathrm{scaled} \mathrm{to} \mathrm{the} \mathrm{peak} \mathrm{of} \mathrm{the} \mathrm{first} \mathrm{EPSC.}$ $C$, Average time course of PPD in control conditions (open circles) and in $2 \mathrm{Ca}_{\mathrm{e}}$ and $40 \mu \mathrm{M} \mathrm{CTZ} \mathrm{(} \mathrm{filled} \mathrm{circles;} \mathrm{four} \mathrm{experiments).} \mathrm{The} \mathrm{CTZ} \mathrm{recovery}$ curve was fit to a double exponential with $A_{\text {fast }}=38 \%, A_{\text {inter }}=39 \%, \tau_{\text {fast }}=25 \mathrm{msec}$, and $\tau_{\text {inter }}=2.4$ sec. $D$, Average time course of PPD in 4 Ca $a_{\mathrm{e}}$ without (open circles) and with $40 \mu \mathrm{M} \mathrm{CTZ} \mathrm{(} \mathrm{filled} \mathrm{circles;} \mathrm{four} \mathrm{experiments).} \mathrm{The} \mathrm{CTZ} \mathrm{recovery} \mathrm{curve} \mathrm{was} \mathrm{fit} \mathrm{to} \mathrm{a} \mathrm{double} \mathrm{exponential} \mathrm{decay} \mathrm{with} \mathrm{amplitudes} A_{\text {fast }}$ $=50 \%, A_{\text {inter }}=52 \%, \tau_{\text {fast }}=23 \mathrm{msec}$, and $\tau_{\text {inter }}=1.7 \mathrm{sec}$.

stimulus trains in a variety of external calcium conditions. Figure 7, $A$ and $B$, shows the accumulation of depression after one or four pulses during a brief $20 \mathrm{~Hz}$ train while decreasing $\mathrm{Ca}_{\mathrm{e}}$ from 4 to $1 \mathrm{~mm}$. We found that $\mathrm{EPSC}_{2} / \mathrm{EPSC}_{1}$ was affected to a greater degree than was EPSC $_{5} /$ EPSC $_{1}$ when external calcium was perturbed. This difference can be more clearly seen when depression is plotted against stimulus pulse number for both high and low $\mathrm{Ca}_{\mathrm{e}}$ (Fig. $7 C$ ). The two curves deviate substantially early in the train, whereas they begin to converge as depression approaches a steady-state value. Thus, transient depression is more sensitive to initial release probability than is steady-state depression, as has been described for other synapses (Markram and Tsodyks, 1996;
Abbott et al., 1997; O’Donovan and Rinzel, 1997; Tsodyks and Markram, 1997).

Under conditions of increased calcium influx and high stimulus frequencies, the calcium-dependent component of recovery was prominent, as demonstrated in Figure 8. By comparing the attenuation in EPSC amplitude during a brief $10 \mathrm{~Hz}$ train, we observed a more pronounced depression in the presence of EGTA-AM, consistent with the hypothesis that residual calcium participated in the recovery from depression. The relationship between depression and stimulus pulse number (Fig. 8B,D) demonstrates that EGTA affects steady-state depression, in contrast to manipulations that affected the probability of release (see above). In 

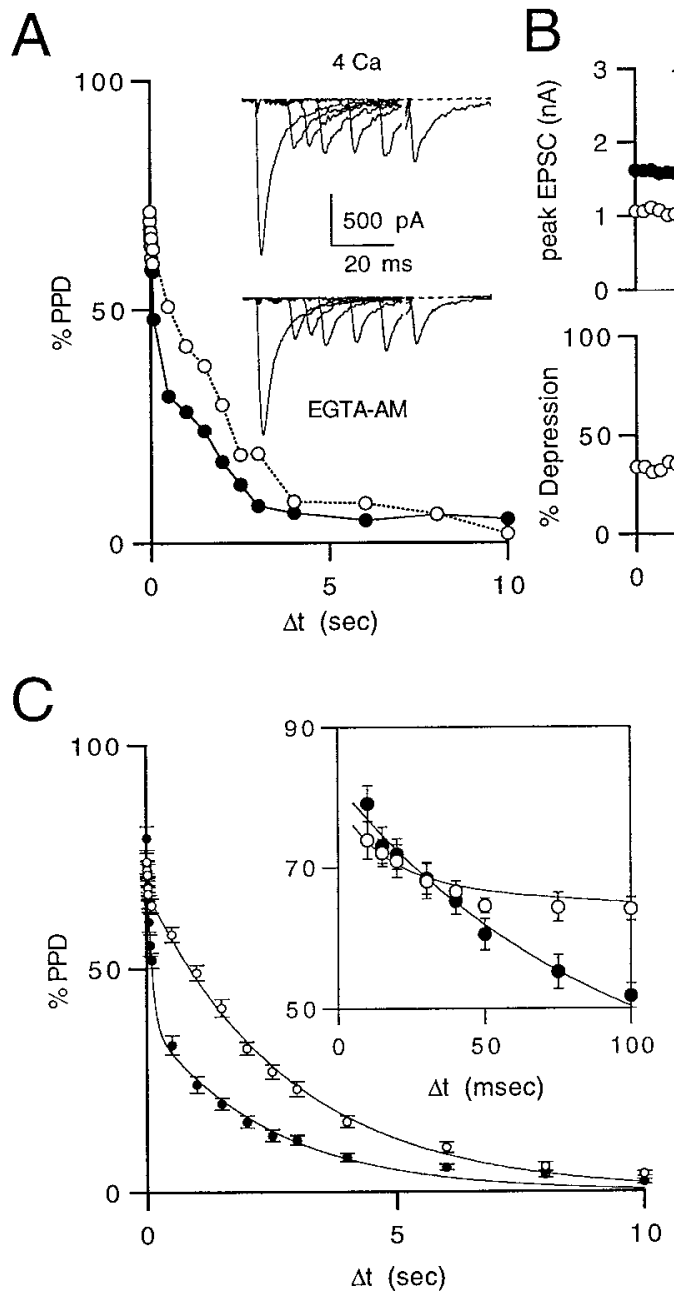
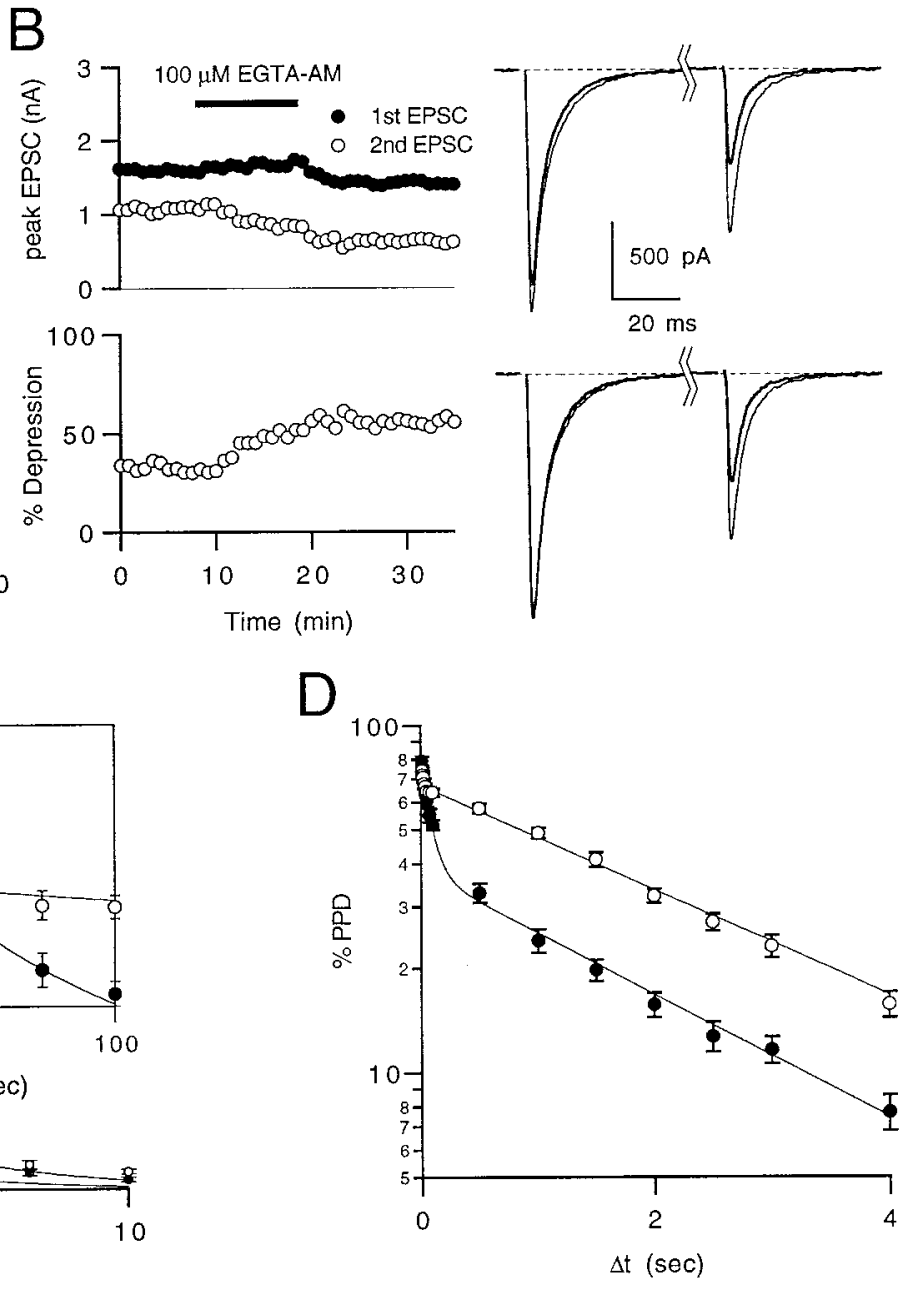

Figure 6. The effect of intracellular EGTA on the rapid recovery phase of depression. A, PPD recovery kinetics in $4 \mathrm{Ca}_{\mathrm{e}}$ before ( filled circles) and after (open circles) exposure to $100 \mu \mathrm{M}$ EGTA-AM. Insets, Synaptic currents for brief interpulse intervals before (top) and after (bottom) loading with EGTA-AM. B, Left, Effects of $100 \mu \mathrm{M}$ EGTA-AM on the control EPSC ( filled circles), the depressed EPSC (open circles), and \%PPD (bottom). Top right, Averages of 10 traces before (thin lines) and after (thick lines) exposure to EGTA-AM. Interpulse interval was 500 msec. Bottom right, Same traces scaled to peak of first EPSC. $C$, Average time course of PPD in $4 \mathrm{Ca}_{\mathrm{e}}$ before (closed circles) and after (open circles; 12 experiments; mean $\pm \mathrm{SEM}$ ) loading with EGTA-AM. Inset, Early interpulse intervals. The PPD recovery curve after loading with EGTA-AM was fit to a double exponential decay with amplitudes $A_{\text {fast }}=17 \%, A_{\text {inter }}=65 \%, \tau_{\text {fast }}=17 \mathrm{msec}$, and $\tau_{\text {inter }}=2.9 \mathrm{sec} . D$, Semilog plot of the data in $C$.

some cases, we observed a partial recovery during the stimulus train (Fig. $8 A$ ), but the magnitude of this effect was highly variable from synapse to synapse.

\section{Simple model for calcium-driven recovery from presynaptic depression}

Based on the experiments described in Figures 2-8, we propose a simple model to account for depression at the climbing fiber synapse. According to this model, a synaptic connection consists of $N_{o}$ independent release sites, each with probability $P_{r}$ of releasing neurotransmitter when an action potential arrives at the presynaptic terminal. Facilitation was not included because paired-pulse enhancement of transmitter release was not observed under conditions of low $P_{r}$ (which would unmask facilitation by reducing depression and enhancing facilitation). The distinction between the availability of the site and the probability that exocytosis occurs can be clarified by separating $P_{r}$ into two components; (1) $p_{o}$ is defined as the probability that a site releases its transmitter given that it is release ready, and (2) $p_{n}$ is the probability that a release site is available to undergo vesicle fusion
(Zucker, 1973; Korn and Faber, 1987). Thus, $P_{r}=p_{o} \cdot p_{n}$, and quantal content $m=N_{o} \cdot P_{r}=N_{o} \cdot p_{n} \cdot p_{o}$. If we let the number of available release sites $N=N_{o} \cdot p_{n}$, then $m=N \cdot p_{o}$. The mean synaptic strength is given by $\operatorname{EPSC}_{1}=N \cdot p_{o} \cdot q$, where $q$ is the magnitude of the average quantal response. If the sites that undergo exocytosis require a nonzero recovery time, then immediately after the first stimulus there are $N \cdot\left(1-p_{o}\right)$ sites capable of releasing neurotransmitter. A second stimulus given just after the first will elicit a response of size $\mathrm{EPSC}_{2}=N \cdot\left(1-p_{o}\right) \cdot p_{o} \cdot q$, provided $p_{o}$ at each site is unchanged and assuming that $p_{n}=0$ at all $N \cdot p_{o}$ sites that underwent exocytosis. This part of the model is identical to a number of other depletion schemes that have been proposed to account for the magnitude of depression (Liley and North, 1952; Takeuchi, 1958; Elmqvist and Quastel, 1965; Betz, 1970). We separated release probability into the two components defined above to clarify the origins of depression in our model. Because both $p_{o}$ and $p_{n}$ are stochastic in nature, experimental procedures based on trial-to-trial variation in quantal content, such as quantal and nonstationary noise analysis, will provide 
A
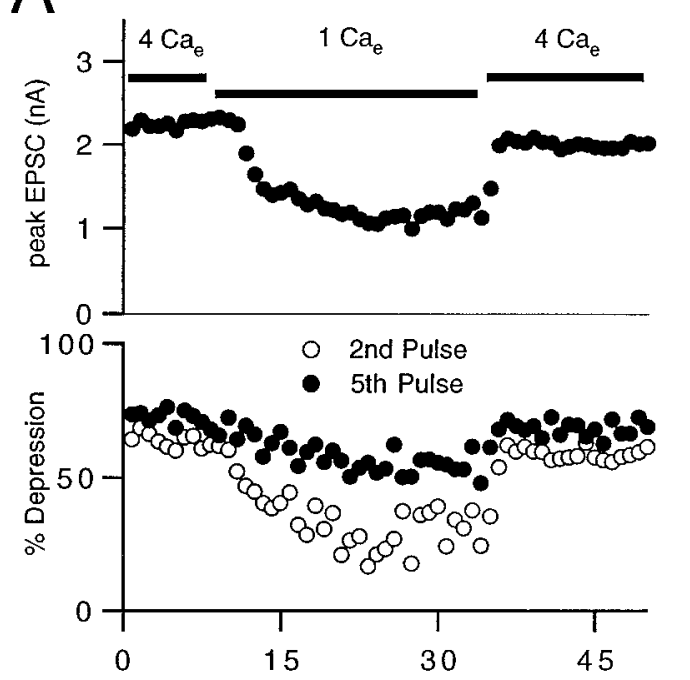

B

Time (min)
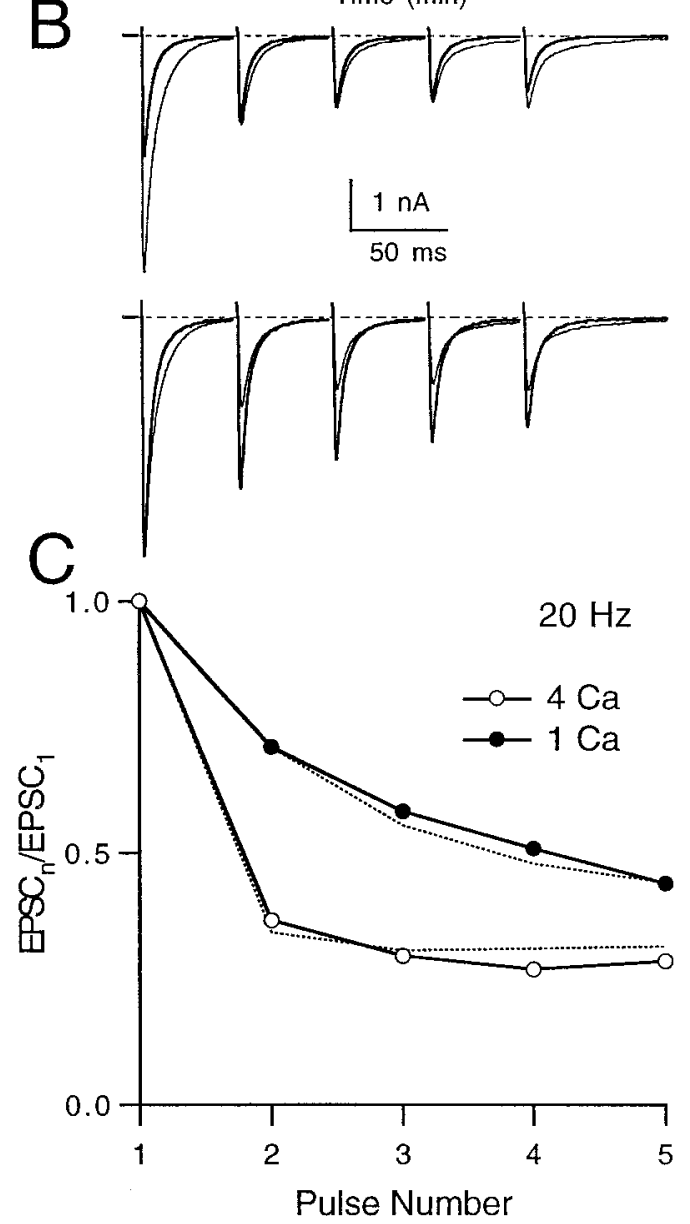

Figure 7. Dynamics of presynaptic depression during stimulus trains. $A$, Top, Peak EPSC for the first pulse in a train of five stimuli given at $20 \mathrm{~Hz}$ while changing from 4 to $1 \mathrm{Ca}_{\mathrm{e}}$. Bottom, Depression of the second pulse relative to the first (open circles) and of the fifth pulse relative to the first (filled circles) during solution exchange. B, Top, EPSC trains in $4 \mathrm{Ca}_{\mathrm{e}}$ (thin lines) and $1 \mathrm{Ca}_{\mathrm{e}}$ (thick lines). Bottom, Same traces normalized to the first EPSC. Traces are averages of 5-10 trials each. $C$, Depression magnitude plotted versus stimulus pulse number for $4 \mathrm{Ca}_{\mathrm{e}}$ (open circles) and $1 \mathrm{Ca}_{\mathrm{e}}$ (closed circles). Dashed lines are predictions from the recovery model (see Results).
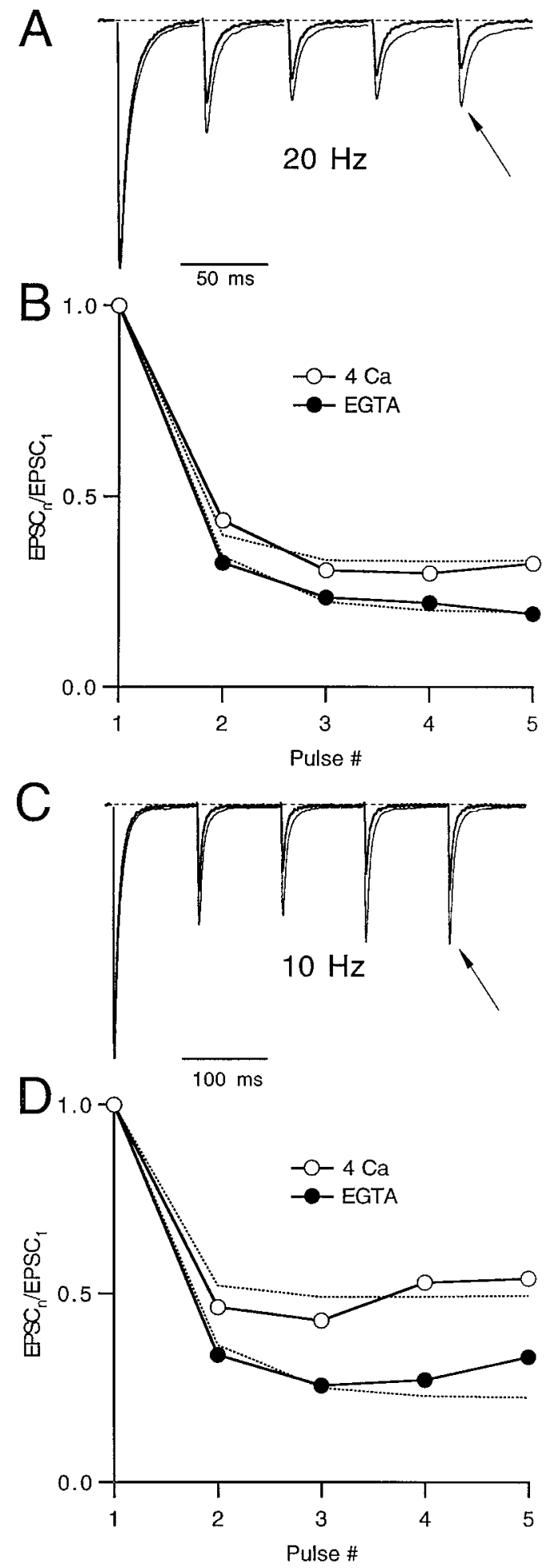

Figure 8. Effects of perturbing presynaptic calcium dynamics on depression during stimulus trains. $A$, EPSC train at $20 \mathrm{~Hz}$ in $4 \mathrm{Ca}_{\mathrm{e}}$ (thin lines) and with EGTA-AM (thick lines). Traces are averages of five trials and normalized to the peak of the first EPSC. The arrow indicates depression in $4 \mathrm{Ca}_{\mathrm{e}} . B$, Depression magnitude plotted versus stimulus pulse number for $20 \mathrm{~Hz}$ train in $4 \mathrm{Ca}_{\mathrm{e}}$ (open circles) and $4 \mathrm{Ca}_{\mathrm{e}}$ and EGTA (filled circles). Dashed lines are predictions from the recovery model (see Results). $C$, Same as $A$ with a $10 \mathrm{~Hz}$ train. Note the scale bar change. $D$, Same as $B$ with a $10 \mathrm{~Hz}$ train. 
estimates of $P_{r}$ but will not distinguish between $p_{n}$ and $p_{o}$ (Kuno, 1964; Zucker, 1973; Bennett and Florin, 1974; Bennett et al., 1976; Bennett and Fisher, 1977; Korn et al., 1982; Korn and Faber, 1987). By considering depletion as solely a reduction in $p_{n}$, depression could be interpreted as either a reduction in the number of available release sites $\left(N=N_{o} \cdot p_{n}\right)$ or as a reduction in release probability $\left(P_{r}=p_{o} \cdot p_{n}\right)$.

Many models of recovery from depression use a first-order process, as in Scheme I, that predicts an exponential (constantrate) recovery, $\operatorname{PPD}(\Delta t)=p_{o} \mathrm{e}^{-\Delta t / \tau}$ :

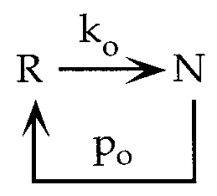

The time constant $\tau=\left(k_{o}\right)^{-1}$ is typically given a value of several seconds, reflecting the time course of the return of release sites to a release-ready state (Liley and North, 1952; Betz, 1970; Magleby, 1987). Scheme I fails to account for the properties of climbing fiber depression that we observe, such as multiexponential recovery and dependence on residual calcium.

By assuming that presynaptic residual calcium binds to a site on the release apparatus causing an acceleration in the rate of recovery, we were able to account for the properties of recovery from depression. We propose that recovery from depression proceeds according to Scheme II. On average, $N \cdot p_{o}$ release sites are activated (and transiently refractory) and therefore must be removed from the available pool. The refractory sites $(R)$ then recover through a calcium-bound intermediate state $(T)$ as represented below:

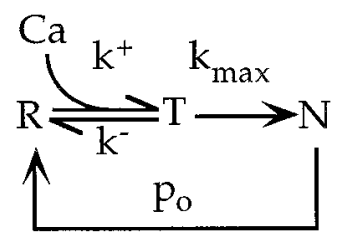

(See Materials and Methods for a mathematical treatment of Scheme II). If the site is in the release-ready state, calcium influx causes release of neurotransmitter with probability $p_{o}$ and drives the release site into a refractory state in which release is not possible (i.e., $p_{n}=0$ ). The site then slowly returns to the releaseready state, and the rate of recovery is enhanced by elevated residual calcium. Figure $9 A$ shows the expected recovery from depression after an action potential. The rapid decay $\left(\tau_{\text {decay }}=\right.$ $100 \mathrm{msec}$ ) of presynaptic residual calcium gives rise to the fast component of recovery. After calcium has returned to resting levels, recovery continues on a slow time scale $\left(\tau_{\text {recov }}=3 \mathrm{sec}\right)$. Figure $9 B$ shows the model predictions superimposed on the PPD data under four different experimental conditions. On an expanded time scale (inset), one can see that the model also successfully accounts for the loss of a fast component when residual calcium transients are reduced by lowering $\mathrm{Ca}_{\mathrm{e}}$ and when residual calcium decay is shortened with EGTA. In the four experimental conditions shown, $p_{o}$ was calculated by extrapolating the PPD curves shown in Figure 4 to $\Delta t=0$. The values used were $p_{o}=$ 0.42, 0.63, 0.81, and 0.78 in $1 \mathrm{Ca}_{\mathrm{e}}, 2 \mathrm{Ca}_{\mathrm{e}}, 4 \mathrm{Ca}_{\mathrm{e}}$, and EGTA, respectively. The parameters $K_{N}, k_{\max }$, and $\tau_{c}$ were chosen to fit recovery in $2 \mathrm{Ca}_{\mathrm{e}}$ and then held fixed for the other conditions. However, $\tau_{c}$ was shortened in the presence of EGTA. Relative calcium influx in either 4 or $1 \mathrm{Ca}_{\mathrm{e}}$ was adjusted to give the best fit.

The predictions of Scheme II were investigated during trains of action potentials to explore further the contribution of residual calcium to steady-state depression and recovery. The effect of changing from 4 to $1 \mathrm{Ca}_{\mathrm{e}}$ on synaptic depression produced by brief stimulus trains is well described by Scheme II (Fig. $7 C$, dashed lines), as is the effect of speeding the decay of presynaptic residual calcium with EGTA-AM (Fig. 8B,D, dashed lines). This model also captured many features of frequency-dependent depression during brief stimulus over a large range of stimulus frequencies, as shown in Figure 10. As the probability of release and calcium influx were increased by elevating $\mathrm{Ca}_{\mathrm{e}}$, steady-state depression increased more steeply with frequency. Scheme II accounted for most of the depression using parameters derived from PPD curves under similar experimental conditions. However, at high frequencies in $4 \mathrm{Ca}_{\mathrm{e}}$, EPSC amplitudes continued to decrease below the predicted values, suggesting that some other process may contribute to depression under these conditions.

\section{Behavior of depression during more realistic spike trains}

We then considered how presynaptic depression would contribute to synaptic strength for realistic activity patterns. Inferior olivary neurons normally fire at $1-4 \mathrm{~Hz}$ in vivo (Armstrong and Rawson, 1979), and climbing fibers are unlikely to be significantly depressed for such conditions. However, many other types of neurons fire irregularly at rates between 0.1 and $100 \mathrm{~Hz}$ (Kuffler et al., 1957; Perkel et al., 1967; Softky and Koch, 1993). We used the climbing fiber synapse as a model to investigate the dynamics of presynaptic depression and the performance of our model during conditions of activation that would be experienced by other types of synapses. Although these experiments were conducted at $24^{\circ} \mathrm{C}$ and do not quantitatively reflect the dynamics of depression that would be experienced in vivo, they are instructive with respect to the model and the qualitative dependence of synaptic strength on the initial probability of release and recovery kinetics. Climbing fibers were stimulated with Poisson spike trains at average rates between 1 and $20 \mathrm{~Hz}$. Figure 11 illustrates climbing fiber depression during a Poisson train for three different experimental conditions. With low external calcium, little steady-state depression was observed at $10 \mathrm{~Hz}$ (Fig. 11A). Increasing external calcium enhanced synaptic depression as expected from the PPD and regular stimulus train experiments (Fig. 11B). When calcium was increased to $4 \mathrm{~mm}$, pulse-to-pulse fluctuations in EPSC amplitude were prominent at $5 \mathrm{~Hz}$ (Fig. $11 C$ ). This striking variability resulted from the interplay between release probability and recovery kinetics. As $p_{o}$ was increased with higher external calcium, depression at high frequencies was augmented. In contrast, recovery from depression was accelerated in high calcium so there was relatively less depression at lower frequencies. The data shown in Figure 11 are examples from single climbing fibers, and we observed a large amount of variability in certain parameters from fiber to fiber. For instance, $p_{o}$ ranged between 0.45 and 0.8 in 2 $\mathrm{Ca}_{\mathrm{e}}$ (with a mean of 0.63 ), whereas other parameters such as $K_{N}$ and $\tau_{c}$ varied to a lesser extent. Synapse-to-synapse variation is not surprising in young rats because climbing fiber synapses undergo elimination around this time (O'Leary et al., 1971; Crepel et al., 1976), and variations in presynaptic parameters may reflect these changes.

Although Scheme II could describe the first few EPSCs in a 

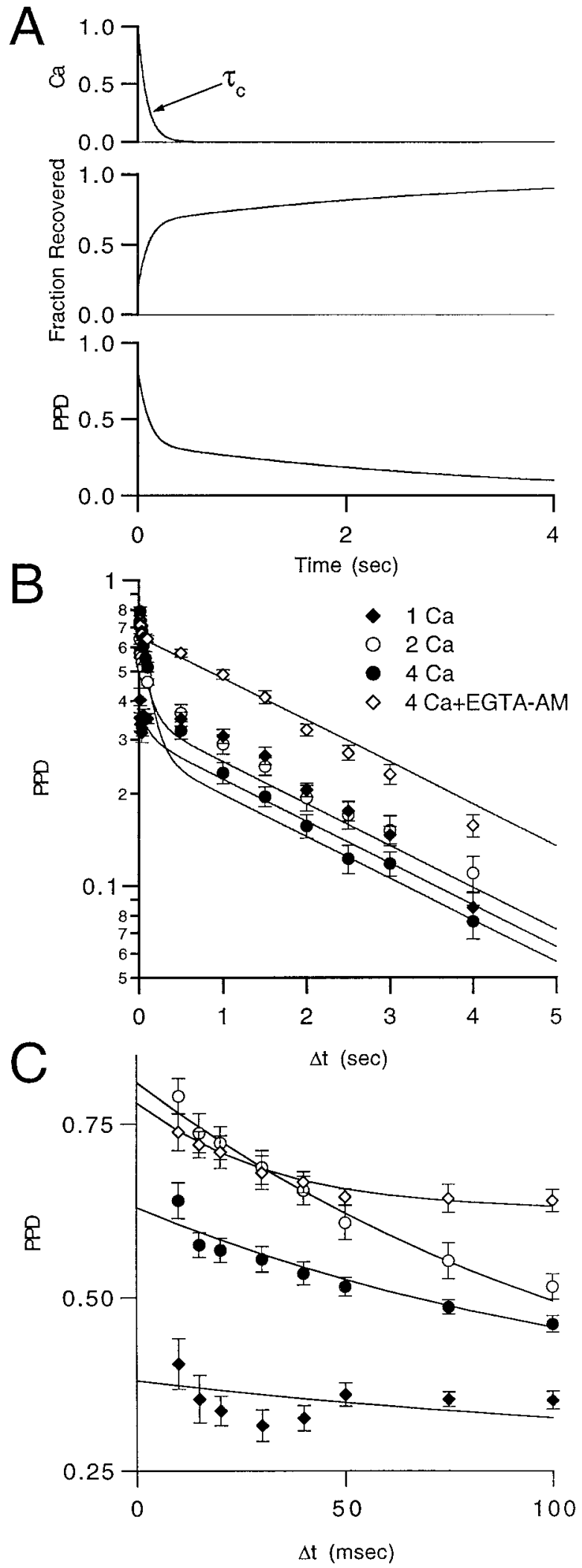

Figure 9. Model for calcium-dependent recovery from presynaptic depression. A, Simulation of presynaptic residual calcium (top), fraction of release sites available (middle), and fraction of depressed sites (bottom) after an action potential. $B$, Summary PPD data fit with the calciumdependent recovery model; $1 \mathrm{Ca}_{\mathrm{e}}$ (filled diamonds), $2 \mathrm{Ca}_{\mathrm{e}}$ (open circles), $4 \mathrm{Ca}_{\mathrm{e}}$ (filled circles), and $4 \mathrm{Ca}_{\mathrm{e}}$ and EGTA (open diamonds). Inset, Same
Poisson train successfully under all conditions tested, a slower recovery component was needed to simulate depression accurately over tens to hundreds of stimuli. During prolonged stimulation of the climbing fiber, we observed a gradual increase in depression that recovered in $<2 \mathrm{~min}$. This long-lived depression has been described previously in other climbing fiber preparations (Rawson and Tilokskulchai, 1981). For simulations of Poisson stimulus trains (Fig. 11), it was necessary to incorporate this slower component of depression. The simplest modification of this scheme is the addition of a separate recovery pathway with slower kinetics:

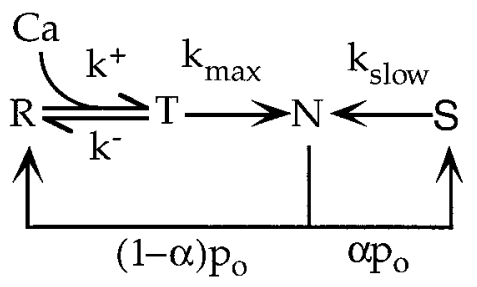

We did not explore the recovery kinetics of the slow pathway $(S)$ in this study, but trains repeated every 2 min showed no signs of rundown. The recovery rate $k_{\text {slow }}$ was therefore taken to be in the range of $10-60 \mathrm{sec}$. The probability that a refractory release site enters state $S$ is defined as $\alpha$. This parameter was adjusted to give the best fit between simulations and Poisson train data. Typical values were $\sim 0.05$, consistent with the observation that a slow depression was prevalent after $\sim 20$ stimuli. Numerical simulations of Scheme II were used in modeling responses to the Poisson stimuli shown in Figure 11 using a first-order Euler integration routine with time steps of $200 \mu \mathrm{sec}$. Simulations of Poisson stimuli captured most of the short-term changes in synaptic efficacy over the time scale ranging from milliseconds to seconds. Interestingly, the magnitude of the additional slow component was inversely correlated with external calcium; lower calcium accentuated the slow component analogous to its effect on the intermediate recovery component.

Figure $12 \mathrm{~A}$ shows the behavior of the calcium-dependent recovery model during the first 10 pulses of a $10 \mathrm{~Hz}$ Poisson stimulus train. The filled circles represent the predicted EPSC magnitudes if no calcium-dependent recovery were to occur but all other parameters were identical. A substantial deviation between the model and the data can be seen within two or three stimuli, indicating that calcium dependence was critical in maintaining synaptic strength during the stimulation. In Figure $12 B$, we plotted the steady-state attenuation of the climbing fiber EPSC during a train of stimuli versus the frequency of stimulation; it is clear that acceleration of recovery from depression substantially increases synaptic strength relative to the calcium-independent recovery model. The attenuation of climbing fiber EPSCs after seven pulses (see Fig. 10) is plotted against stimulus frequency on the same graph for comparison (open circles). Even for the highly simplified solution to Scheme II, calcium-dependent recovery

$\leftarrow$

data on an expanded time scale. Data points are mean \pm SEM. Model parameters for fits are $k_{o}=0.314 \mathrm{sec}^{-1} ; k_{\max }=8 \mathrm{sec}^{-1} ; K_{N}=1.05 ; \tau_{c}=$ $120 \mathrm{msec}$ (20 msec in EGTA); and $p_{o}=0.38,0.63,0.81$, and 0.78 in $1 \mathrm{Ca}_{\mathrm{e}}$, $2 \mathrm{Ca}_{\mathrm{e}}, 4 \mathrm{Ca}_{\mathrm{e}}$, and EGTA, respectively. Ca influx increased by a factor of 2.5 going from 2 to $4 \mathrm{Ca}_{\mathrm{e}}$ and decreased by a factor of 3.3 going from 2 to $1 \mathrm{Ca}_{\mathrm{e}} . C$, Same PPD data on an expanded time scale to compare rapid decay components. 


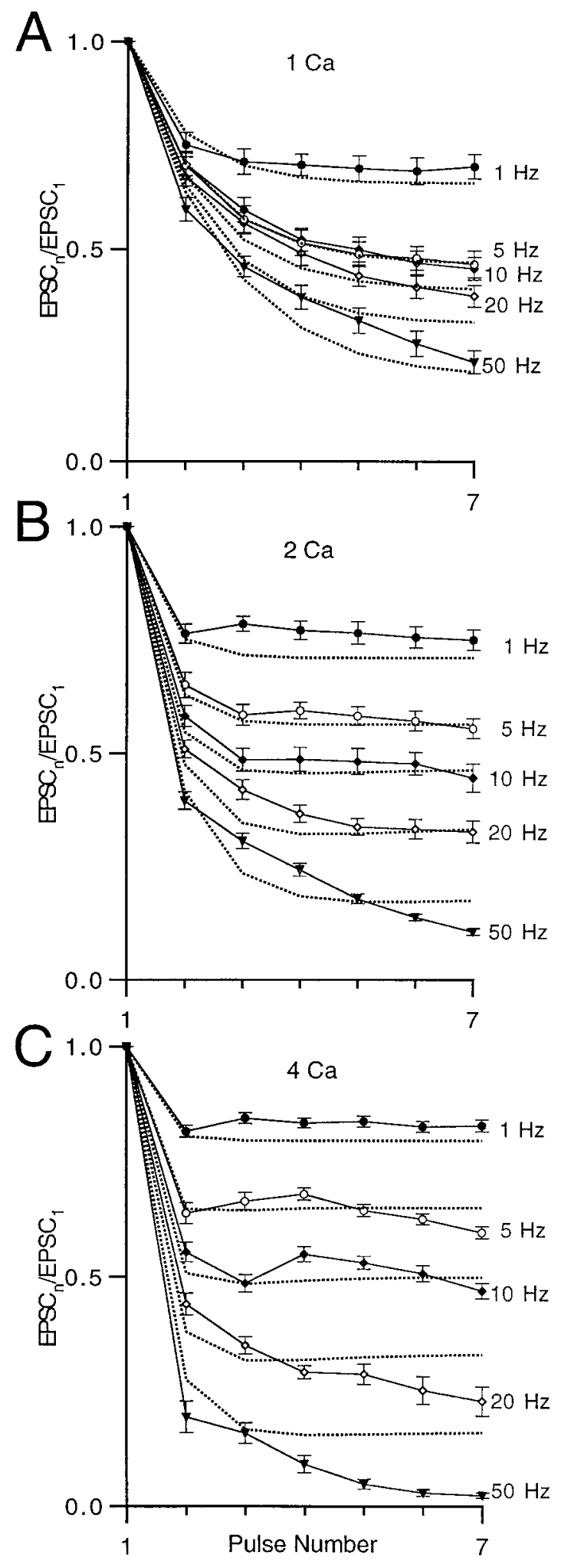

Figure 10. Experimental summary of depression during stimulus trains under various external calcium conditions. $A$, Relative depression in $1 \mathrm{Ca}_{\mathrm{e}}$ during trains of stimuli given at various frequencies for the second through seventh pulse in a train. Data are mean \pm SEM; $1 \mathrm{~Hz}$ (filled circles; $n=6$ ), $5 \mathrm{~Hz}$ (open circles; $n=6$ ), $10 \mathrm{~Hz}$ ( filled diamonds; $n=12$ ), $20 \mathrm{~Hz}$ (open diamonds; $n=11$ ), and $50 \mathrm{~Hz}$ (filled triangles; $n=7$ ). $B$, Relative depression in $2 \mathrm{Ca}_{\mathrm{e}} . C$, Relative depression in $4 \mathrm{Ca}_{\mathrm{e}}$. provides a better prediction of steady-state behavior than does a constant-rate recovery model (Scheme I).

\section{DISCUSSION}

We found that climbing fiber to Purkinje cell synapses display robust use-dependent presynaptic depression that recovers on three characteristic time scales. Our principal finding is that the rapid component of recovery is remarkably fast (tens to hundreds of milliseconds) and is driven by presynaptic residual calcium. This rapid component accelerates recovery from depression, particularly during periods of high frequency activity, thereby maintaining synaptic efficacy under conditions that would otherwise render synapses ineffective. Such calcium-dependent recovery from depression is likely present at many types of synapses and may account for anomalous features of transmission during stimulus trains at the squid giant synapse, the neuromuscular junction, and other synapses.

\section{Possible mechanisms for depression and recovery}

A number of candidate mechanisms could underlie the presynaptic depression described here. Intermediate and slow recovery phases similar to the depression observed during long stimulus trains (Fig. 11) have been described in a variety of preparations (Rawson and Tilokskulchai, 1981; Abbott et al., 1997; Varela et al., 1997) and may reflect depletion and recovery of a reserve pool of vesicles that feeds the readily-releasable pool (von Gersdorff and Matthews, 1997). Previous studies have implicated endocytotic recycling of vesicular membrane as the rate-limiting step in recovery from exocytosis on time scales corresponding to these two components of depression (Betz and Wu, 1995; von Gersdorff and Matthews, 1997). The rapid component of recovery from depression we observe here is similar to that of endocytosis in neuroendocrine cells, both in kinetics and calcium dependence (Artalejo et al., 1995, 1996). This suggests that elevated levels of residual calcium could speed the recovery from depression by enhancing a rapid component of endocytosis. Alternatively, release sites may be transiently refractory independent of endocytosis (Dobrunz et al., 1997), and elevated calcium may drive the site into an exocytosis-competent state through mechanisms such as vesicle docking or priming (Schweizer et al., 1995). Further experiments will be needed to determine the mechanism responsible for calcium-dependent recovery from depression.

\section{Comparison with other synapses}

Although synaptic depression has been extensively studied for many decades, the calcium-dependent component of recovery from depression we report here has not been widely observed. This does not mean, however, that rapid recovery is a unique feature of the climbing fiber synapse. At synapses such as the squid giant synapse and the neuromuscular junction, it is difficult to study depression in isolation because they display other usedependent processes including facilitation, augmentation, and post-tetanic potentiation (Magleby, 1987). Facilitation enhances transmission for hundreds of milliseconds after stimulation, obscuring any rapid phase of recovery. Moreover, facilitation is calcium dependent (Zucker, 1989), so manipulating presynaptic calcium dynamics (i.e., by introducing EGTA as in Figs. 6, 9) would affect both facilitation and recovery from depression. In addition, because depression after a single stimulus is not prominent at the squid giant synapse and the neuromuscular junction, depression was often studied using prolonged trains of stimuli, in 
A

$\left.\begin{array}{c}0.5 \\ 0.0 \\ -0.5\end{array}\right] \ldots$

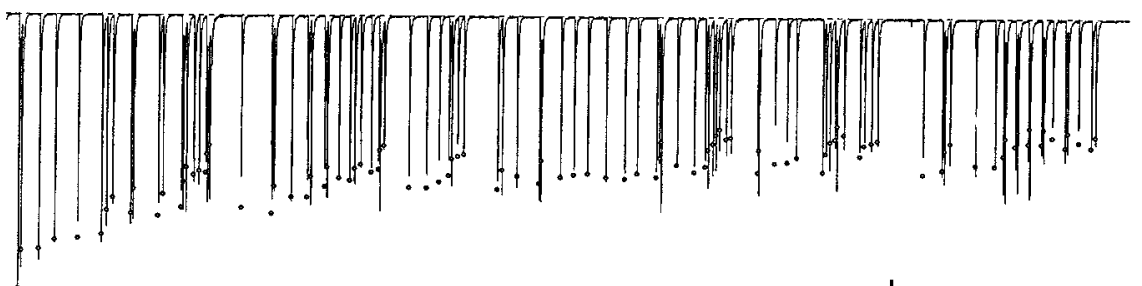

B
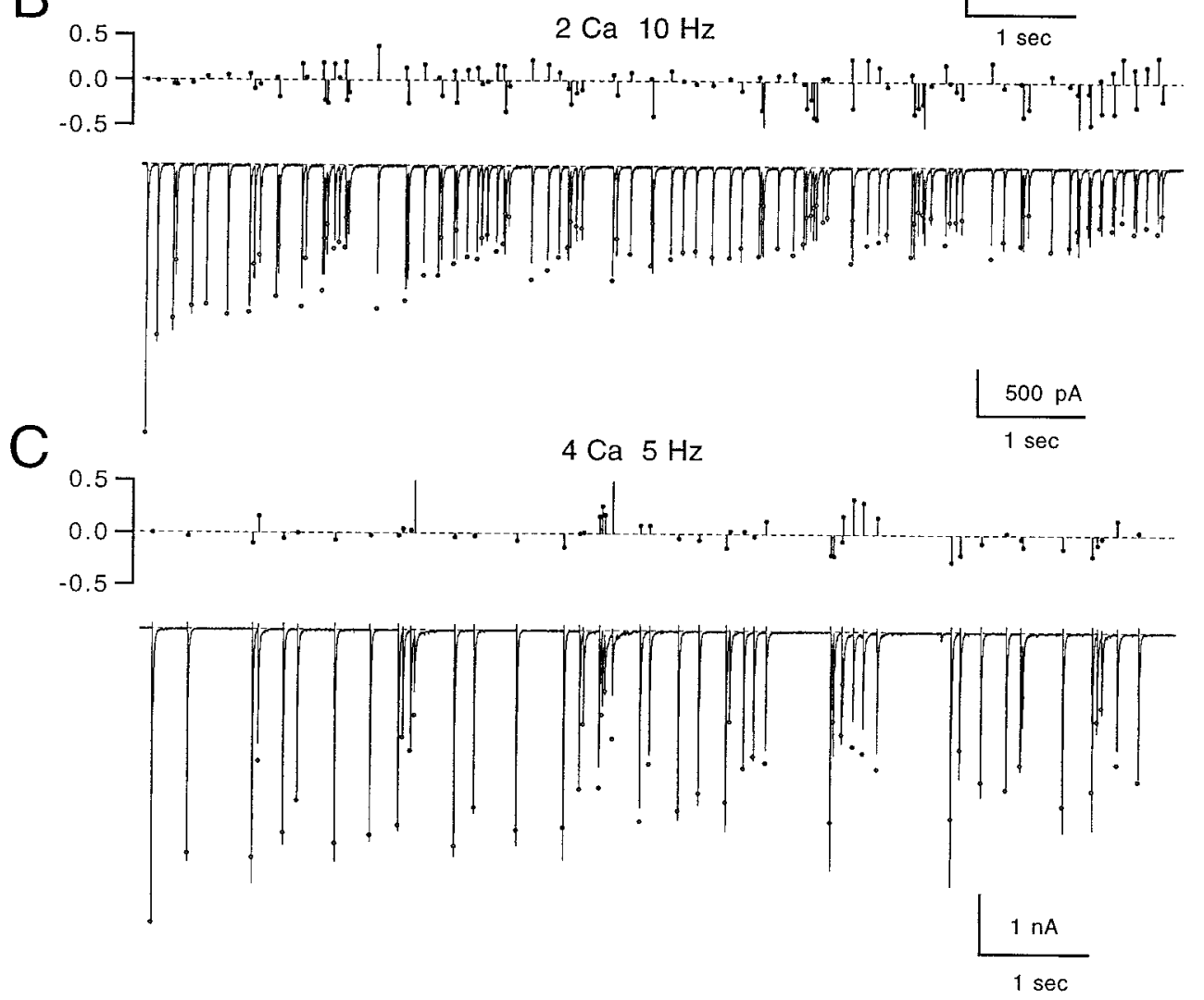

Figure 11. Examples of depression during Poisson train stimuli under various external calcium conditions. $A$, Climbing fiber stimulation in $1 \mathrm{Ca}_{\mathrm{e}}$ using a random spike train with average rate of $10 \mathrm{~Hz}$. Open circles are predictions of the recovery model (Scheme II, see Materials and Methods). Relative errors between the simulation and the data are shown above. Model parameters were $k_{o}=0.31 \mathrm{sec}^{-1}, k_{\max }=7.5$ $\sec ^{-1}, K_{N}=0.9, \tau=100 \mathrm{msec}, p_{o}=$ $0.16, k_{\text {slow }}=0.1$, and $\alpha=0.08$. Calcium influx was reduced by 3.7 -fold relative to $2 \mathrm{Ca}_{\mathrm{e}}$. $B$, Same as $A$ in $2 \mathrm{Ca}_{\mathrm{e}}$. Model parameters were $k_{o}=0.31 \mathrm{sec}^{-1}, k_{\max }$ $=7.5 \mathrm{sec}^{-1}, K_{N}=0.8, \tau=100 \mathrm{msec}, p_{o}$ $=0.5, k_{\text {slow }}=0.1$, and $\alpha=0.06 . C$, Same as $A$ in $4 \mathrm{Ca}_{\mathrm{e}}$. Model parameters were $k_{o}=0.31 \mathrm{sec}^{-1}, k_{\max }=8.5 \mathrm{sec}^{-1}$, $K_{N}=0.75, \tau=115 \mathrm{msec}, p_{o}=0.65$, $k_{\text {slow }}=0.1$, and $\alpha=0.03$. Calcium influx was increased by $60 \%$ relative to $2 \mathrm{Ca}_{\mathrm{e}}$. All data are single trials. which calcium-independent mechanisms may dominate (Charlton et al., 1982; Swandulla et al., 1991). Thus, it is not surprising that there was no direct evidence of a fast calcium-dependent component of recovery from depression at such synapses.

However, a number of observations at these synapses hinted at the existence of a calcium-dependent recovery from depression. The constant-rate depletion model (Scheme I) for recovery from depression consistently overestimated depression during brief stimulus trains (Takeuchi, 1958; Betz, 1970), prompting the suggestion that recovery from depression was accelerated during periods of high activity (Kusano and Landau, 1975). Similar findings were also reported at sensory synapses involved in Aplysia gill withdrawal (Byrne, 1982; Gingrich and Byrne, 1985) and at the cricket cercal sensory system (Hill and Jin, 1998). The calcium dependence of recovery from depression we report here would account for the properties of depression at the squid giant synapse, the neuromuscular junction, and at sensory synapses from Aplysia and cricket for brief stimulus trains. It therefore seems plausible that rapid calcium-dependent recovery from depression is a feature common to many synapses.

\section{Models of recovery from presynaptic depression}

We found that a simple model of presynaptic depression with calcium-dependent recovery (see Materials and Methods; Fig. 9) could account for climbing fiber synaptic plasticity under a wide variety of experimental conditions. We chose to model presynaptic depression as a transient decrease in the probability that a release site is capable of exocytosis $\left(p_{n}\right)$ because this scheme allowed for a parsimonious description of our data with few free parameters. The number of available release sites and the average probability of release are explicitly represented (Scheme II), so experimental manipulations that affect these presynaptic parameters have clear predictions embodied in the model. By separating the probability that a release site undergoes exocytosis $\left(p_{o}\right)$ from the probability that the site is release ready $\left(p_{n}\right)$, recovery dynamics could be explained adequately by changing only release 

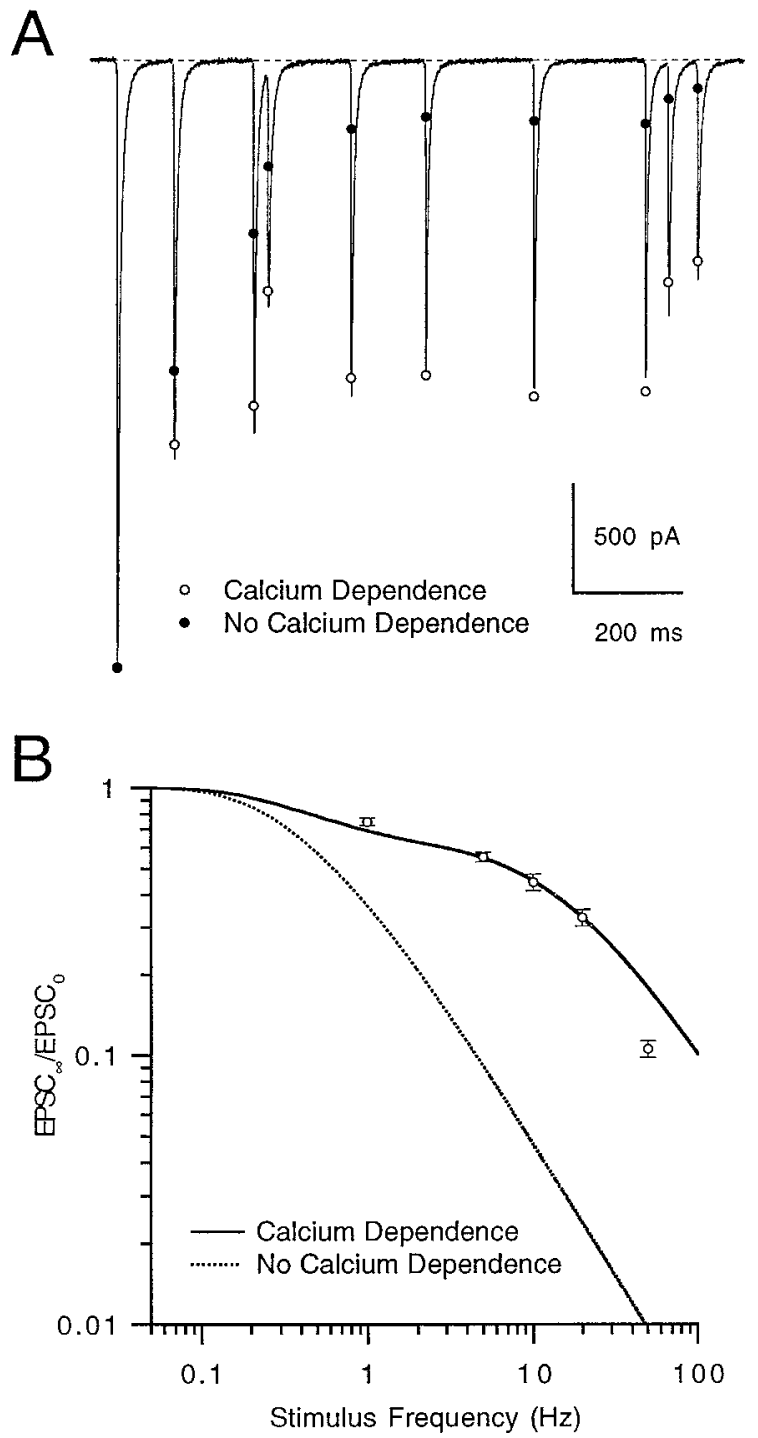

Figure 12. Behavior of presynaptic depression with and without calcium dependence. A, Brief Poisson stimulus train in $2 \mathrm{Ca}_{\mathrm{e}}$. Closed circles are predictions of the calcium-independent recovery model (Scheme I), and open circles are predictions of the calcium-dependent recovery model (Scheme II). B, Steady-state attenuation of synaptic strength during stimulus trains of various frequencies according to the calcium-dependent recovery model (solid line) and the calcium-independent recovery model (dotted line). Data points correspond to $\mathrm{EPSC}_{7} / \mathrm{EPSC}_{0}$ from Figure $10 \mathrm{~B}$. Model parameters were $k_{o}=0.31 \mathrm{sec}^{-1}, k_{\max }=8.5 \mathrm{sec}^{-1}, K_{N}=1, \tau=100$ msec, and $p_{o}=0.6$. For prolonged stimulation, where scheme III is required, additional depression is expected.

site availability. It is important to note that, according to this scheme, depression can be considered to be the result of either a change in the number of available release sites or a change in the probability of release, depending on the precise definition of these parameters (see Results).

The model presented here has several limitations compared with alternative approaches. For instance, it is not designed to fit long trains of EPSCs by adjusting arbitrary free parameters. Other schemes have recently been proposed to accomplish this goal using a mathematically efficient representation of facilitation and depression, without explicit reference to the probability of release or the number of functional release sites (Varela et al., 1997). Furthermore we made a number of simplifying assump- tions. For mathematical simplicity, we chose a single exponential decay of residual calcium similar to the transient observed at parallel fibers (Regehr and Atluri, 1995). Also, we did not consider a number of potentially important biophysical issues, such as calcium diffusion within the presynaptic terminal, interactions with calcium-binding proteins, calcium cooperativity of recovery from depression, or additional release-site refractory states. We did not incorporate these factors into our model because they are not yet understood at this synapse.

Despite these limitations, we believe that the modeling approach taken here has several attractive features. First, with relatively few free parameters, the model can account for recovery from depression in multiple experimental conditions, while simultaneously predicting depression during short stimulus trains over a 50-fold frequency range. Second, recovery is based on a reasonable physical scheme concerning transitions of the release apparatus. Third, the model can be solved analytically for both PPD recovery and accumulation of depression during trains. These simple analytical solutions provide an efficient means of exploring parameter space and investigating the sensitivity of depression to various changes in presynaptic variables.

Another property of models that describe synaptic plasticity solely in terms of facilitation and depression is that they can combine facilitation and rapid recovery from depression into a single enhancement term. This can be a useful simplification because these two processes occur on similar time scales and have parallel effects on synaptic transmission. The model presented here, however, separates release probability from vesicle availability, thus allowing for the possibility that two physically distinct processes can occur on short time scales, both acting to augment synaptic strength. Further experiments are necessary to dissect the two processes and determine whether they confer different properties on synaptic plasticity.

\section{Implications for synaptic transmission}

Dependence of recovery on presynaptic calcium concentration confers certain novel dynamic properties on synaptic transmission. At very low frequencies, residual calcium is negligible, and recovery from depression proceeds slowly. As the presynaptic activation rate increases, residual calcium builds, and the recovery rate increases accordingly, thereby counteracting the depression caused by release-site depletion. This mechanism provides a frequency-dependent "boosting" similar to that of facilitation, but one that occurs at lower frequencies. Figure $12 \mathrm{~A}$ demonstrates this frequency-dependent enhancement by superimposing the outputs of both the calcium-dependent recovery model and a simple constant-rate depletion model compared with the actual behavior of the climbing fiber synapse. The difference between the two models is pronounced after only a few stimuli. Figure $12 \mathrm{~B}$ quantifies steady-state depression as a function of frequency for both Schemes I and II. Two aspects of use-dependent depression are apparent. First, depression low-pass filters steady-state synaptic strength with a characteristic frequency set by the recovery rate. Second, calcium-dependent recovery increases the characteristic frequency toward the maximal recovery rate, thereby sustaining synaptic efficacy at low to intermediate frequencies $(0.1-10 \mathrm{~Hz})$. It is interesting to note that climbing fibers fire at average rates within this range of frequencies in vivo (Ito, 1984), suggesting that calcium-dependent recovery may be important in maintaining a strong synaptic connection. If this calciumdependent recovery is present at synapses that fire at higher rates 
(10-100 Hz), it would enhance steady-state synaptic strength by $>10$-fold.

\section{REFERENCES}

Abbott LF, Sen K, Varela JA, Nelson SB (1997) Synaptic depression and cortical gain control. Science 275:220-222.

Adler EM, Augustine GJ, Duffy SN, Charlton MP (1991) Alien intracellular calcium chelators attenuate neurotransmitter release at the squid giant synapse. J Neurosci 11:1496-1507.

Armstrong DM, Rawson JA (1979) Activity patterns of cerebellar cortical neurones and climbing fibre afferents in the awake cat. J Physiol (Lond) 289:425-448.

Artalejo CR, Henley JR, McNiven MA, Palfrey HC (1995) Rapid endocytosis coupled to exocytosis in adrenal chromaffin cells involves $\mathrm{Ca}^{2+}$, GTP, and dynamin but not clathrin. Proc Natl Acad Sci USA 92:8328-8332.

Artalejo CR, Elhamdani A, Palfrey HC (1996) Calmodulin is the divalent cation receptor for rapid endocytosis, but not exocytosis, in adrenal chromaffin cells. Neuron 16:195-205.

Atluri PP, Regehr WG (1996) Determinants of the time course of facilitation at the granule cell to Purkinje cell synapse. J Neurosci 16:5661-5671.

Bennett MR, Fisher C (1977) The effect of calcium ions on the binomial parameters that control acetylcholine release during trains of nerve impulses at amphibian neuromuscular synapses. J Physiol (Lond) 271:673-698.

Bennett MR, Florin T (1974) A statistical analysis of the release of acetylcholine at newly formed synapses in striated muscle. J Physiol (Lond) 238:93-107.

Bennett MR, Florin T, Pettigrew AG (1976) The effect of calcium ions on the binomial statistic parameters that control acetylcholine release at preganglionic nerve terminals. J Physiol (Lond) 257:597-620.

Betz WJ (1970) Depression of transmitter release at the neuromuscular junction of the frog. J Physiol (Lond) 206:629-644.

Betz WJ, Wu LG (1995) Kinetics of synaptic-vesicle recycling. Curr Biol 5:1098-1101.

Byrne JH (1982) Analysis of synaptic depression contributing to habituation of gill-withdrawal reflex in Aplysia californica. J Neurophysiol 48:431-438.

Charlton MP, Smith SJ, Zucker RS (1982) Role of presynaptic calcium ions and channels in synaptic facilitation and depression at the squid giant synapse. J Physiol (Lond) 323:173-193.

Crepel F, Mariani J, Delhaye-Bouchaud N (1976) Evidence for a multiple innervation of Purkinje cells by climbing fibers in the immature rat cerebellum. J Neurobiol 7:567-578.

Davies CH, Pozza MF, Collingridge GL (1993) CGP 55845A: a potent antagonist of $\mathrm{GABA}_{\mathrm{B}}$ receptors in the CA1 region of rat hippocampus. Neuropharmacology 32:1071-1073.

Deisz RA, Prince DA (1989) Frequency-dependent depression of inhibition in guinea-pig neocortex in vitro by $\mathrm{GABA}_{\mathrm{B}}$ receptor feed-back on GABA release. J Physiol (Lond) 412:513-541.

Del Castillo J, Katz B (1954) Quantal components of the end-plate potential. J Physiol (Lond) 124:560-573.

Diamond JS, Jahr CE (1995) Asynchronous release of synaptic vesicles determines the time course of the AMPA receptor-mediated EPSC. Neuron 15:1097-1107.

Dobrunz LE, Stevens CF (1997) Heterogeneity of release probability, facilitation, and depletion at central synapses. Neuron 18:995-1008.

Dobrunz LE, Huang EP, Stevens CF (1997) Very short-term plasticity in hippocampal synapses. Proc Natl Acad Sci USA 94:14843-14847.

Eccles JC, Katz B, Kuffler SW (1941) Nature of the "endplate potential" in curarized muscle. J Physiol (Lond) 124:574-585.

Eccles J, Llinas R, Sasaki K (1964) Excitation of cerebellar Purkinje cells by the climbing fibers. Nature 203:245-246.

Eccles JC, Llinas R, Sasaki K (1966a) The excitatory synaptic action of climbing fibers on the Purkinje cells of the cerebellum. J Physiol (Lond) 182:268-296.

Eccles JC, Llinas R, Sasaki K, Voorhoeve PE (1966b) Interaction experiments on the responses evoked in Purkinje cells by climbing fibres. J Physiol (Lond) 182:297-315.

Elmqvist D, Quastel DMJ (1965) A quantitative study of end-plate potentials in isolated human muscle. J Physiol (Lond) 178:505-29.

Feng TP (1941) Studies on the neuromuscular junction. Chin J Physiol 16:341-372.

Gingrich KJ, Byrne JH (1985) Simulation of synaptic depression, post- tetanic potentiation, and presynaptic facilitation of synaptic potentials from sensory neurons mediating gill-withdrawal reflex in Aplysia. J Neurophysiol 53:652-669.

Hashimoto K, Kano M (1998) Presynaptic origin of paired-pulse depression at climbing fiber-Purkinje cell synapses in the rat cerebellum. J Physiol (Lond) 506:391-405.

Hatt H, Smith DO (1976) Synaptic depression related to presynaptic axon conduction block. J Physiol (Lond) 259:367-393.

Herrington J, Bookman RJ (1995) Pulse control V4.5: IGOR XOPs for patch clamp data acquisition. Miami: University of Miami.

Hill AAV, Jin P (1998) Regulation of synaptic depression rates in the cricket cercal sensory system. J Neurophysiol 79:1277-1285.

Ito M (1984) The cerebellum and neural control. New York: Raven.

Konnerth A, Llano I, Armstrong CM (1990) Synaptic currents in cerebellar Purkinje cells. Proc Natl Acad Sci USA 87:2662-2665.

Korn H, Faber DS (1987) Regulation and significance of probabilistic release mechanisms at central synapses. In: Synaptic function (Edelman GM, Gall WE, Cowan WM, eds), pp 57-108. New York: Wiley.

Korn H, Mallet A, Triller A, Faber DS (1982) Transmission at a central inhibitory synapse. II. Quantal description of release, with a physical correlate for binomial n. J Neurophysiol 48:679-707.

Kuffler SW, Fitzhugh R, Barlow HB (1957) Maintained activity in the cat's retina in light and darkness. J Gen Physiol 40:683.

Kuno M (1964) Mechanism of facilitation and depression of the excitatory synaptic potential in spinal motoneurones. J Physiol (Lond) 175:100-112.

Kusano K, Landau EM (1975) Depression and recovery of transmission at the squid giant synapse. J Physiol (Lond) 245:13-32.

Liley AW, North KAK (1952) An electrical investigation of effects of repetitive stimulation on mammalian neuromuscular junction. J Neurophysiol 16:509-527.

Lundberg A, Quilisch H (1953) On the effect of calcium on presynaptic potentiation and depression at the neuro-muscular junction. Acta Physiol Scand 30[Suppl 111]:121-129.

Magleby KL (1987) Short-term changes in synaptic efficacy. In: Synaptic function (Edelman GM, Gall WE, Cowan WM, eds), pp 21-56. New York: Wiley.

Markram H, Tsodyks M (1996) Redistribution of synaptic efficacy between neocortical pyramidal neurons. Nature 382:807-810.

Mintz IM, Sabatini BL, Regehr WG (1995) Calcium control of transmitter release at a cerebellar synapse. Neuron 15:675-688.

Neher E, Augustine GJ (1992) Calcium gradients and buffers in bovine chromaffin cells. J Physiol (Lond) 450:273-301.

O’Donovan MJ, Rinzel J (1997) Synaptic depression: a dynamic regulator of synaptic communication with varied functional roles. Trends Neurosci 20:431-433.

O'Leary JL, Inukai J, Smith JM (1971) Histogenesis of the cerebellar climbing fiber in the rat. J Comp Neurol 142:377-392.

Otsuka M, Endo M, Nonomura Y (1962) Presynaptic nature of neuromuscular depression. Jpn J Physiol 8:573-584.

Patil PG, Brody DL, Yue DT (1998) Preferential closed-state inactivation of neuronal calcium channels. Neuron 20:1027-1038.

Perkel DH, Gerstein G, Moore G (1967) Neuronal spike trains and stochastic point processes. Biophys J 7:391-418.

Perkel DJ, Hestrin S, Sah P, Nicoll RA (1990) Excitatory synaptic currents in Purkinje cells. Proc R Soc Lond [Biol] 241:116-121.

Ramon y Cajal S (1911) Histologie du systeme nerveux de l'homme et des vertebres. Paris: Maloine.

Rawson JA, Tilokskulchai K (1981) Suppression of simple spike discharge of cerebellar Purkinje cells by impulses in climbing fibre afferents. Neurosci Lett 25:125-130.

Regehr WG, Atluri PP (1995) Calcium transients in cerebellar granule cell presynaptic terminals. Biophys J 68:2156-2170.

Regehr WG, Delaney KR, Tank DW (1994) The role of presynaptic calcium in short-term enhancement at the hippocampal mossy fiber synapse. J Neurosci 14:523-537.

Schulz AR (1994) Enzyme kinetics. Cambridge, England: Cambridge UP.

Schweizer FE, Betz H, Augustine GJ (1995) From vesicle docking to endocytosis: intermediate reactions of exocytosis. Neuron 14:689-696.

Smith DO, Hatt H (1976) Axon conduction block in a region of dense connective tissue in crayfish. J Neurophysiol 39:794-801.

Softky WR, Koch C (1993) The highly irregular firing of cortical cells is inconsistent with temporal integration of random EPSPs. J Neurosci 13:334-350.

Swandulla D, Hans M, Zipser K, Augustine GJ (1991) Role of residual 
calcium in synaptic depression and posttetanic potentiation: fast and slow calcium signaling in nerve terminals. Neuron 7:915-926.

Takahashi M, Kovalchuk Y, Attwell D (1995) Pre- and postsynaptic determinants of EPSC waveform at cerebellar climbing fiber and parallel fiber to Pukinje cell synapses. J Neurosci 15:5693-5702.

Takeuchi A (1958) The long-lasting depression in neuromuscular transmission of frog. Jpn J Physiol 12:102-113.

Tank DW, Regehr WG, Delaney KR (1995) A quantitative analysis of presynaptic calcium dynamics that contribute to short-term enhancement. J Neurosci 15:7940-7952.

Thies RE (1965) Neuromuscular depression and the apparent depletion of transmitter in mammalian muscle. J Neurophysiol 28:427-442.

Thomson AM, Deuchars J, West DC (1993) Large, deep layer pyramidpyramid single axon EPSPs in slices of rat motor cortex display paired pulse and frequency-dependent depression, mediated presynaptically and self-facilitation, mediated postsynaptically. J Neurophysiol 70:2354-2369.

Trussell LO, Fischbach GD (1989) Glutamate receptor desensitization and its role in synaptic transmission. Neuron 3:209-218.

Trussell LO, Zhang S, Raman IM (1993) Desensitization of AMPA receptors upon multiquantal neurotransmitter release. Neuron 10:1185-1196.
Tsodyks MV, Markram H (1997) The neural code between neocortical pyramidal neurons depends on neurotransmitter release probability. Proc Natl Acad Sci USA 94:719-723.

Varela JA, Sen K, Gibson J, Fost J, Abbott LF, Nelson SB (1997) A quantitative description of short-term plasticity at excitatory synapses in layer 2/3 of rat primary visual cortex. J Neurosci 17:7926-7940.

von Gersdorff H, Matthews G (1997) Depletion and replenishment of vesicle pools at a ribbon-type synaptic terminal. J Neurosci 17:1919-1927.

von Gersdorff H, Schneggenburger R, Weis S, Neher E (1997) Presynaptic depression at a calyx synapse: the small contribution of metabotropic glutamate receptors. J Neurosci 17:8137-8146.

Yamada KA, Rothman SM (1992) Diazoxide blocks glutamate desensitization and prolongs excitatory currents in rat hippocampal neurones. J Physiol (Lond) 458:409-423.

Yamada KA, Turetsky DM (1996) Allosteric interactions between cyclothiazide and AMPA/kainate receptor antagonists. Br J Pharmacol 117:1663-1672.

Zucker R (1973) Changes in the statistics of transmitter release during facilitation. J Physiol (Lond) 229:787-810.

Zucker RS (1989) Short-term synaptic plasticity. Annu Rev Neurosci 12:13-31. 